\title{
Autonomic impairment of patients in coma with different Glasgow coma score assessed with heart rate variability.
}

Mario Estévez-Báez ${ }^{\mathrm{a}}$ Calixto Machado ${ }^{\mathrm{a}}$, Benjamín García-Sánchez ${ }^{\mathrm{b}}$, Valia Rodríguez Reynaldo Alvarez-Santana ${ }^{\mathrm{c}}$, Adam Schiavi ${ }^{\mathrm{d}}$, Gerry Leisman ${ }^{\mathrm{e}}$, Julio Montes-Brown ${ }^{\mathrm{f}}$, José Mario Estévez-Carrera ${ }^{\mathrm{g}}$, Eduardo Arrufat-Pié ${ }^{\mathrm{h}}$

${ }^{a}$ Institute of Neurology and Neurosurgery, Department of Clinical Neurophysiology, Havana, Cuba.

${ }^{\mathrm{b}}$ Cuban Center of Neurosciences, Havana, Cuba.

c "Hermanos Ameijeiras" Hospital, Department of Pathology, Havana, Cuba.

d nesthesiology and Critical Care Medicine, Neurosciences Critical Care Division, Johns Hopkins Hospital, Baltimore, Maryland, USA.

${ }^{\text {e }}$ School of Health Sciences, University of Haifa, Haifa, Israel.

${ }^{\mathrm{f}}$ Department of Medicine \& Health Science. University of Sonora, Mexico.

g University Hospital "Dr. Luis Diaz Soto", Department of Neurophysiology, Havana, Cuba.

h Institute of Basic and Preclinical Sciences, "Victoria de Girón", Havana, Cuba.

\section{ACCEPTED MANUSCRIPT}

Mario Estévez-Báez_ marioestevez@infomed.sld.cu

Calixto Machado cmachado_2000@yahoo.com

Benjamín García-Sánchez ㅁ.garciabenja@gmail.com

Valia Rodríguez ㅁaia.rodriguez@gmail.com

Reynaldo Alvarez-Santana reynaldo.alvarez@infomed.sld.cu

Adam Schiavi aschiav1@jhmi.edu

Gerry Leisman g.leisman@alumni.manchester.ac.uk

Julio Montes-Brown $\quad$ montesbrownj@gmail.com

José Mario Estévez-Carrera josemestevez@nauta.cu

Eduardo Arrufat Pié $\quad$ arrufatp@infomed.sld.cu 


\section{Abstract}

Primary objective: To assess and compare the functional state of the autonomic nervous system in healthy individuals with patients in coma using measures of heart rate variability (HRV), and to evaluate its efficiency in predicting mortality.

Research design: Retrospective group comparison study of patients in coma, classified into two subgroups, according to their Glasgow coma score, with a healthy control group.

Methods and procedures: HRV indices were calculated from 7 minutes of free of artifacts electrocardiograms using the Hilbert-Huang method in the spectral range 0.02-0.6 Hz. A special procedure was applied to avoid the effect of confounding factors. Stepwise multiple regression logistic analysis (SMLRA), followed by ROC curve analysis were applied to evaluate predictions.

Results: Progressive reduction of HRV associated with deepening of coma was confirmed and a mortality score model including three spectral HRV indices: absolute power values of the very low, low frequency, and the power in normalized units of the very high frequency bands $(0.4-0.6 \mathrm{~Hz})$. The SMLRA model showed sensitivity of 95.65\%, specificity of $95.83 \%$, positive predictive value of $95.65 \%$, and overall efficiency of $95.74 \%$.

Conclusions: $\mathrm{HRV}$ is a reliable method to assess the integrity of the neural control of the caudal brainstem centres upon the heart, of patients in coma, and predict mortality. 


\section{Keywords}

Heart rate variability coma Autonomic nervous system

Coma

Hilbert-Huang transform

Empirical mode decomposition

Intrinsic frequency

Sympathovagal modulation

Glasgow coma scale 


\section{MAIN TEXT}

\section{Introduction}

Assessment of the functional state of the autonomic nervous system (ANS) in healthy humans and patients using different indices of heart rate variability (HRV) have proved to be useful, sensitive, reliable and non-invasive methods [1-4]. It has been shown that the ANS functional state predicts responsiveness in disorders of consciousness [5]. Multiple indices of HRV calculated in the time, frequency or informational domains have been studied in patients in coma with different objectives: to assess brainstem dysfunction [6], to assess brain death [7-9], differentiation of autonomic nervous activity in different stages of coma [10], diagnosis of dysautonomia after traumatic brain injuries (TBI) [11], calculation and description of HRV indices of patients in coma [12] correlation of the HRV parameters with the Glasgow coma score (GCS) [13-16], prediction or prognosis of the outcome in TBI, acute cerebral vascular disease, or critically ill neurosurgical patients [17-23], association of HRV indices with mortality in patients with TBI [24-32], and prediction of life saving interventions in patients with trauma [22, 33-37].

However, HRV indices have shown to be under the influence of multiple demographic and physiological variables (age, gender, heart rate, blood pressure, respiratory rate) becoming confounding factors that need to be considered in these studies $[16,21,23$, 38-41]. In addition, in patients in coma the presence of non-Gaussian, nonlinear, and nonstationary processes associated with the multiple mechanisms regulating the autonomic

control of the cardiovascular system cannot be ruled out. Consequently, the assessment of HRV indices, particularly those calculated in the frequency domain, should be carried out 
using methods developed to handle non-Gaussian, non-linear and non-stationary signals. The traditional approach using the Fourier analysis for the study of spectral components of HRV has been successfully and widely used since its introduction [1, 42, 43], but strictly speaking this method is limited to the study of linear systems.

One of the well-known methods introduced to analyse nonlinear and non-stationary biomedical signals is the Hilbert-Huang transform (HHT) [44-48]. The HHT method consists of a two-step analysis. The first step is the empirical mode decomposition (EMD) that allows the extraction of modal components called intrinsic mode functions (IMFs), which are frequency-modulated signals processes. The second step includes the application of the Hilbert transform (HT) to obtain from the extracted IMFs the corresponding analytic functions, and then, to calculate the instantaneous values of key spectral features: frequency, power, and phase. The HHT has been successfully used to study electroencephalographic (EEG) signals [49-54], for the study of the electrocardiogram (ECG) [55-62], and heart rate variability (HRV) analysis [63-76].

In previous studies we have reported the suitability of HRV indices calculated in the time, informational, and frequency domains for assessing the functional state of ANS in patients in coma, using traditional approaches $[13,15,16]$. In this study we include patients in coma classified into two subgroups according to their Glasgow coma scores (GCS). Moreover, we introduce the HHT method for the analysis of HRV indices in the frequency domain, to avoid the possible biases associated with the use of Fourier methods, apply a procedure to correct for confounding factors on HRV indices, and evaluate the effect of this methodological approach on the efficiency of HRV measures in predicting mortality in patients in coma. 


\section{Methods}

\section{Subjects}

A total of 63 patients in coma, admitted to the intensive care unit at a tertiary care teaching centre ("Hermanos Ameijeiras" Hospital, Havana), with Glasgow Coma score (GCS) values between 3 and 8 were initially included in the study. After a careful analysis of their antecedents, clinical status, and medication, 13 patients were excluded who: were over 75 years old, demonstrated diabetes mellitus, cardiac ischemic disease, cardiac arrhythmias, presence of non-sinus atrial electrocardiographic cardiac rhythm, use of drugs as hypnotics, alpha or beta-blockers, or others with known action on the autonomic system. Three patients with a GCS $=3$ were excluded because they were receiving inotropic drugs or vasoconstrictors to stabilize the blood pressure. The final sample included 23 patients with GCS from 6 to 8 , and 24 patients with GCS from 3 to 5 . A computed tomography (CT) scan of the brain was performed in all patients. All patients were mechanically ventilated. A group of 33 healthy subjects with ages and gender in the same ranges of the group of patients was considered as the control group. Conventionally, in this study the groups will be referred as "Control", "Glas68", and "Glas35". Written informed consent was obtained from the control volunteers, and from the patients's relatives. The Ethical Committees of the Institute of Neurology and Neurosurgery, the "Hermanos Ameijeiras" Hospital, and of the Cuban Centre of Neurosciences, approved the study, and the investigation was carried out according to the Declaration of Helsinki.

\section{ECG recording}


The electrocardiogram was recorded with the system MEDICID-06 (Neuronic S.A., Havana, Cuba) with disposable electrodes placed on the thoracic wall in positions CM2 and V5, using a sampling frequency of $200 \mathrm{~Hz}$. The ECG was recorded in patients and in healthy control subjects for 60 minutes. The respiratory rate (RRate) in the patients was obtained from the values of the general monitoring equipment of the ICU. Healthy control subjects breathed spontaneously during the recordings, and the values of their RRate were obtained using the values calculated from a general monitor device (Doctus VI, ICID SA, Cuba).

\section{ECG analysis}

The $200 \mathrm{~Hz}$ sampling rate of the ECG imposed a 5 milliseconds resolution of the Rwave timings. To avoid the resulting quantisation errors in R-wave detection, due to the reduced HRV observed in patients in coma [16], we digitally resampled the ECG signal at 1 $\mathrm{kHz}$, using the Matlab function "interp.m". Next, the interpolated ECG values were exported in ASCII format to a software tool developed by our staff (MEB) written in Delphi version 7 (MultiTools version 3.1.2 2009-2018), for visual inspection, detection of the "R-peaks", and editing. This process was always checked and corrected when it was necessary by two members of the staff (MEB and BGS).

\section{Pre-processing of $R$ - $R$ interval sequences}

To transform the original ordinal sequences of ECG R-R intervals (RRi), into a proper temporal series, an interpolation method was applied using cubic splines with a resampling frequency of $4 \mathrm{~Hz}$, using the Matlab function "interp1.m”. For the HRV analysis series of ECG R-R intervals (RRi) of 420 seconds duration, free of RRi artifacts, were selected, as it is described in a previous report [16]. 


\section{Calculation of HRV indices}

\section{Time domain HRV indices}

For this study the mean value of the RRi series (MRRi), the standard deviation of the RRi (SDRR), and the root mean square of successive differences of R-R intervals (RMSSD), were calculated, as recommended [1,4]. The total variation of the tachograms was calculated as the difference of the maximum and minimum value (W) of the R-R intervals in the sequence. The number of R-R intervals with distinct values (nDRRs) observed in the tachograms for the RRi sequences was also calculated, and a ratio (NRatio) was computed for each tachogram using the expression:

$$
\text { NRatio }=n D R R s / n R R s
$$

where nRRs is the total number of R-R intervals observed in the R-R tachograms. These two last indices have not been described by others, but we considered them potentially useful to better characterize the RRi tachograms in patients with very low HRV.

\section{Informational domain HRV indices}

The complexity of the RRi series was calculated using the procedure described in a previous report [16] with the Shannon's entropy index (ShaEn), considered an informational domain index [77], using the expression:

$$
H=-\sum_{i=1}^{N} p_{i} \log _{2} p_{i}
$$

where $\mathrm{p}_{\mathrm{i}}$ is the probability of every possible value of the duration of an $\mathrm{RRi}$, and $\mathrm{N}$ is the total number of samples [78-80]. If all the observed events would have the same probability 
(equiprobable), then the maximal ShaEn would be 11, and if all the RRIs would have the same value, ShaEn should be 0 .

\section{Empirical mode decomposition (EMD) of RRi series}

Resampled RRi series were submitted to a nonlinear, non-stationary and fully datadriven decomposition into monotonic intrinsic mode functions (IMFs), using a highly developed algorithm of EMD, known as complete ensemble empirical mode decomposition with adaptive noise (CEEMDAN) [81] and recently improved [47]. The implementation of this algorithm in Matlab code and published for free public downloading on the website www.bioingenieria.edu.ar/grupos/ldnlys was used in this study. Following the concepts of harmonic theory, to consider an IMF as corresponding to a valid frequency for HRV analysis, only those IMFs showing at least 10 complete cycles for the total series duration (420 seconds in our case) were accepted, as recommended [1], and it also was removed for the analysis the first extracted IMF, that showed oscillations over the upper limit of spectral HRV frequencies considered in this study $(0.6 \mathrm{~Hz})$. The use of the EMD for the analysis of the spectral components of HRV has been reported by many authors. So, in this section, for reasons of space, we are not including the particularities of the sifting process of the EMD and other details of the Hilbert-Huang method that can be found elsewhere [49, 63, 68, 73, 75, 82, 83]. Instead, we include a schematic diagram showing the different steps that were carried out for the different procedures included in this study (see Figure 1). The Matlab software version R2017a 9.2.0.538062 (The Mathworks, Inc.) was used for the processing of the HilbertHuang method and other calculations in this study. 
Each extracted valid intrinsic mode function (IMF) was submitted to the Hilbert transformation. This method can be applied to the IMFs, because they are monotonic (monocomponent) signals [44]. For each Hilbert transformed IMF the instantaneous frequencies and their corresponding instantaneous values of energy, expressed as the power spectral density were calculated.

With analytic signals it is important to understand the notion of instantaneous indices obtained from the IMFs. An analytic signal is a complex signal with a one-sided spectrum that preserves all information contained in the original signal [84]. The application of the Hilbert transform is a relatively easy way to obtain an analytic signal, that we refer to here as $\mathrm{Z}(\mathrm{t})$. Once we have it, we can see that

$$
Z(t)=X(t)+i Y(t)
$$

where $\mathrm{X}(\mathrm{t})$ is the input time series (the IMF in this case), and $\mathrm{iY}(\mathrm{t})$ the Hilbert transform of $\mathrm{X}(\mathrm{t})$.

Several instantaneous indices of this analytic signal can now be obtained using the following expressions:

$$
P(t)=\left[X(t)^{2}+Y(t)^{2}\right] ; \quad \theta(t)=\arctan \left(\frac{Y(t)}{X(t)}\right) ; \quad \omega(t)=\frac{d \theta(t)}{d(t)}
$$

where $\mathrm{P}(\mathrm{t})$ is the instantaneous energy power, $\theta(\mathrm{t})$ is the instantaneous phase, and $\omega(\mathrm{t})$ is the instantaneous frequency.

The instantaneous values of power and spectral frequency of each extracted IMF were used for the ulterior calculations of the spectral indices. These values were included in a 2-D matrix. 


\section{Frequency domain HRV indices}

The lower limit for HRV spectral frequencies in this study was fixed in $0.02 \mathrm{~Hz}$ and the upper limit in $0.6 \mathrm{~Hz}$. Spectral HRV indices estimations of the power spectral density expressed in absolute values, relative PSD expressed in normalized units (\%), and centre frequency values, detected in the different frequency bands, were calculated from the sorted 2-D matrix by the frequency column in ascending order, taking in consideration that in the sorted 2-D matrix the instantaneous power values corresponded to their original instantaneous frequencies. Accordingly, the Matlab function "sortwows.m" was used. The mathematical expression used for these calculations was:

$$
E(a b s)=\sum_{i=\min }^{\max } D F_{i}
$$

where "min" represents the lower limit value of the spectral range of the band, "max" the upper limit, and $\mathrm{DF}_{\mathrm{i}}$ are the discrete spectral frequencies of the spectra. The acronyms used for these indices were P-VHF for the very low frequency band; P-LF for the low frequency band; P-HF for the high frequency band; P-VHF for the very high frequency band, and P-Tot for the whole power spectral density in the frequency range from 0.02 to $0.6 \mathrm{~Hz}$.

For the calculations of HRV spectral indices of relative PSD, expressed in normalized units (\%), the following expression was used:

$$
E(\text { rel })=\frac{E(\text { abs })_{\text {band }}}{E(\text { Total })} * 100 ; \text { (6) }
$$

where $\mathrm{E}(\mathrm{abs})$ band is the absolute energy of the particular band, and $\mathrm{E}($ Total) is the sum of the energy of all the spectral bands. For these indices the acronyms used were the acronyms of 
the corresponding bands, preceded by the prefix "nu-", meaning normalized units (nu-VLF, nu-LF, nu-HF, and nu-VHF).

The ratio of the absolute values in the LF band and HF bands were also calculated and the acronym for this index was LF/HF.

The centre frequencies of the different valid IMFs (2 to 6) were calculated as the mean value of the 1,680 instantaneous frequencies of each IMF. Acronyms used were: cfIMF-2, cf-IMF-3, cf-IMF-4, cf-IMF-5, and cf-IMF-6.

\section{Hilbert marginal spectra}

The Hilbert marginal spectra (HMS) were calculated mainly for graphical representation. For these calculations a function in Matlab coded by one of us [85] was developed. This function allows the selection of a user-defined frequency resolution for the spectrum (in this case we used $0.002 \mathrm{~Hz}$ ), that can be useful for visual and quantitative comparisons with power spectra obtained by other methods, as those based in the Fourier analysis.

\section{Grand mean averages of the PSD}

Grand averages of the HMS spectra obtained for each of the three methods were calculated in the investigated frequency range. For each discrete spectral frequency of the HMS spectra, the mean \pm standards error of the mean were also calculated and plotted with the grand mean averages of the PSD for graphical visual analyses, using a procedure described elsewhere [16, 86, 87]. 
To assess, and correct when necessary, the possible effect of the different confounding factors on the HRV indices, a statistical approach was used generally following in general the methods in a recent report applied to the study of epileptic patients [88]. The influence of gender, age, respiratory rate (RRate), systolic blood pressure (SBP), diastolic blood pressure (DBP), and the reciprocal values of the heart rate, the mean heart inter-beat period duration (MRRi), were assessed to investigate the effect of the covariation of those factors. Gender was coded as a binary variable, with zero representing female and one representing male. A multiple linear regression model according the following formula,

$$
y=\beta_{0}+\beta_{1} x_{1}+\beta_{2} x_{2}+\beta_{3} x_{3}+\beta_{4} x_{4}+\beta_{5} x_{5} ;(7)
$$

where $y$ would be the adjusted HRV index, $\beta_{0}, \beta_{1}, \beta_{2}, \beta_{3}, \beta_{4}$, and $\beta_{5}$, the regression coefficients of the factors gender ( $\left.\mathrm{x}_{1}\right)$, age $\left(\mathrm{x}_{2}\right), \mathrm{SBP}\left(\mathrm{x}_{3}\right), \mathrm{DBP}\left(\mathrm{x}_{4}\right)(\mathrm{SBP})$, and MRRi ( $\left.\mathrm{x}_{5}\right)$, was computed for the HRV indices. The validity of the linear models was assessed using an F-test to prove the null hypothesis that the regression coefficients $\beta_{1}, \beta_{2}, \beta 3, \beta_{4}$, and $\beta_{5}$ were all equal to zero, or to say that the model was constant, as expressed by:

$$
y=\beta_{0}
$$

Then, a t-test for each individual regression coefficient served to determine if the covariation of the associated factor with the HRV index was found to be significant. If the Fstatistic resulted non-significant at least at the $\mathrm{p}<0.05$ level, then the HRV index did not require adjustment. Additionally, the residuals of the linear model were calculated as the differences between the observed values, and the values predicted by the model. If the obtained adjustment was to be considered valid, then it was expected that their distribution was normal, and it was assessed with the Kolmogorov-Smirnov test. Finally, after a 
satisfactory result of the before mentioned test, the calculated residuals became the adjusted values for the HRV index and could be submitted to statistic comparisons between the groups.

\section{Statistical analysis}

The results of the calculations of the studied indices are presented as means and standard deviations. All the examined indices in the study were tested for normality of their distributions using the Kolmogorov-Smirnov test, and normalized using appropriate procedures when necessary. A value of $\mathrm{p}<0.05$ was considered statistically significant for all tests. For comparisons of gender proportions between groups the chi-squared test was used. The Pearson's moment product correlation index, or the Spearman's rank index was calculated to establish the degree of the strength of the relationships between different factors and the HRV indices. For comparisons of other indices between groups the one-way ANOVA test was used, and the post hoc Scheffe's test was considered to determine possible differences between groups. For the adjustment procedure of the effect of confounding factors, multiple regression analysis, the t-Statistic, and the Kolmogorov-Smirnov tests were used to statistically ascertain the convenience or not to implement the procedure, as was described in the topic of adjustment of HRV indices. As in some patients in coma, the fluctuations of the values of the PSD do not show a clear definition of peaks, the significance of the presence of indistinct peaks on the Hilbert marginal spectra was assessed using the Fisher's g-statistic [89, 90]. Univariate logistic regression models were preliminary constructed to assess significant HRV indices associated with mortality. A multivariate logistic regression analysis with forward stepwise entry of variables using Wald statistics was performed to recognize variables that would independently predict mortality, including 
as covariates all the HRV indices calculated in this study using original or adjusted values when it was necessary. Efficiency of the different investigated indices to predict mortality was defined as: total number of correct classifications / number of patients. Receiver operator curve (ROC) analysis and area under curve (AUC) analysis were used to determine the adequacy of the prediction models (univariate or multivariate) for mortality and the best compromise between sensitivity and specificity. All the statistical analyses were performed using the software STATISTICA (StatSoft, Inc. data analysis software system, version 10. www.statsoft.com ) and the IBM SPSS statistic software (Version 23).

\section{Results}

\section{Demographical and vital physiological indices}

The demographic and some vital physiological indices of the studied groups are shown in Table 1. Statistically significant differences for age, gender, systolic and diastolic blood pressures were not found. Significant differences were detected for the respiratory rate that was higher in both groups of patients in coma, and for the mean heart period duration (MRRi) that resulted in significantly higher results for the control group. The brain aetiology of the patients is detailed in Table 2 .

\section{Correlation analysis}

The values of the correlation analysis between the demographic and physiological indices considered as confounding factors in this study are shown in Table 3, demonstrating significant values with the HRV indices, which were more frequent for the factors MRRi, respiratory rate, and age. 


\section{Empirical mode decomposition and Hilbert transform}

The process of EMD, using the iCEEMDAN algorithm of the R-R tachograms is illustrated in Figure 2, showing the results obtained for a control healthy subject and a patient with a GCS $=3$. The tachograms of both subjects showed very clear differences in the corresponding ranges of amplitude of the oscillations of successive R-R intervals, which reflect the variability of the tachograms. In the healthy control this range was approximately from 700 to 900 milliseconds, since in the patient in coma it was between 585 and 625 milliseconds. Besides, there we also found notable differences in the amplitude values of the extracted IMFs, and the number of oscillations of some of them, particularly for the IMF-2 and IMF-3 which were higher than those observed for the same IMFs of the healthy control. Such pattern of differences was generally observed between the healthy controls and the patients in coma, and were more evident for patients of the Glas35 group.

In Figure 3 the values obtained for the instantaneous values of the PSD and the corresponding instantaneous frequencies of the same control and patient shown in Figure 2 are represented. The PSD values of the healthy subject fluctuated during the recording time, but it resulted evident that the intensity (power) of the instantaneous values in the patient in coma were highly reduced in all the IMFs. The previously noted higher number of oscillations in the IMF-2 of the EMD decomposition (see Figure 2) were also reflected in the instantaneous values of the PSD, almost showing a constant presence throughout the duration of the analysed time, though with very low intensity values, while in the healthy control the values fluctuated along the 420 seconds, presenting peaks of more or less intensity separated occasionally by very low values. These characteristics for the PSD instantaneous values calculated with the Hilbert transform, were also observed as a rule when visually comparing 
the results of the healthy controls with those of the patients in coma, particularly with those of the Glas35 group.

\section{Quantitative analysis of HRV indices}

The comparative analysis of the HRV indices calculated in the time domain without adjustments (see Table 4), showed significant differences between the values calculated for the control group and the groups of patients. The post hoc Scheffe's test only detected significant differences between the two patient's groups for the maximal variation (W) and the number of R-R intervals with different values in the tachograms (nDRRs). As expected, the MRRi index resulted higher, and both the SDNN and the RMSSD, were reduced in patients in coma. The range (W), the nDRRs, and the NRatio were significantly higher in the control group. The Shannon entropy, resulted significantly higher in the healthy controls than in the patients, but this index showed significant differences between the two groups of patients, being significantly higher in the Glas68 group (see Table 4).

The analysis for the calculated spectral HRV indices, expressed as absolute values of the PSD, showed significant differences in all the explored bands, with significant higher values for the healthy controls, but significant differences between the patients' groups were only detected for the P-LF index and the total power index P-Tot, that were significantly lower in the Glas35 group. The spectral indices expressed in normalized units showed significant differences between controls and patients. The values of the nu-VLF index were significantly higher in the two groups of patients, particularly in the Glas68 group, that resulted even significantly higher than those in the Glas35 group. The nu-LF values were significantly reduced in the two groups of patients, as was also observed for the nu-HF index. The nu-VHF index, on the contrary, showed significant higher values in the two groups of 
patients in coma, but these values were significantly higher in the Glas35 group compared with those of the Glas68 group. Curiously, the LF/HF ratio index did not show any difference between the groups (see Table 4).

The values of the centre frequency of the instantaneous values obtained from the Hilbert transform corresponding to the first extracted modal component (IMF-1) were deprecated because their values were higher to the upper limit fixed for the exploration of the spectral frequencies in this study $(0.6 \mathrm{~Hz})$, and then considered as possible "noise", as was mentioned earlier. Notwithstanding, we report here the calculated values observed in the three groups for this IMF-1 modal component. In the healthy controls were $0.573 \pm 0.04$, for the Glas68 group were $0.670 \pm 0.10$, and for the Glas35 group $0.661 \pm 0.1$. Significant increments of the indices corresponding to the IMF-2, IMF-3, and IMF-4 were found for the two groups of patients compared with the control group, but without differences between the values of both groups of patients. No significant differences were observed for the IMF-5 and IMF-6 (see Table 4).

The procedure to ascertain the convenience of applying adjustments to HRV indices, proved to be necessary in $11(50.0 \%)$ of the $22 \mathrm{HRV}$ indices. The summary of the different calculations carried out is shown in Table 5. For reasons of space, only some of the HRV indices, are included in the table, but the whole analysis can be accessed in a supplementary material that can be downloaded from the web: https://www.researchgate.net/publication/325130068 . As shown in Table 5, two HRV indices that had values indicating the necessary adjustment (P-VLF and nu-LF). For the PVLF index the confounding factors that significantly contributed were the age and the diastolic blood pressure, while for the nu-LF index the effect of the respiratory rate only 
resulted significant. For the adjustment procedure all the coefficients of the multiple regression model ( $\beta$ estimates) were included, as demanded by the multiple linear regression method. The other 3 HRV indices, where adjustment was not justified were also included in Table 5 (nu-VLF, P-VHF, and nu-VHF). Moreover, for the nu-VHF index, the $\beta$ estimate for the factor MRRi resulted significant, but as the F-statistic was non-significant, the adjustment was not justified.

The results after adjustment of the 11 indices which required it, demonstrated that the observed changes for the nu-LF, and the nu-HF indices did not show significant differences between groups (see Figure 4). The adjustment did not change the statistical results observed before the adjustment for the MRRi index. The SDNN and the RMSSD indices only achieved significant results for the Glas35 group after adjustment. The Shannon entropy index only showed significant differences for the Glas35 group, and did not show differences between the groups of patients, as was detected before correction of the index (see Table 4). The spectral indices of the absolute power P-VLF, P-LF, P-HF, and P-Tot only showed significant differences for the Glas35 group, and the index cf-IMF-2 detected differences of the two groups of patients compared with the control group, but not between them, as had been detected before the adjustment (see Table 4).

\section{Grand mean average of spectra}

The grand mean averages of the spectra obtained for the three groups are shown in Figure 5. There were three remarkable issues that can be emphasized. The first was the marked reduction of the PSD for the two groups of patients, which was even more intense in the Glas35 group. The second was the fact that the peaks of the HRV spectra observed for the control healthy subjects were progressively, not only reduced in magnitude, but even 
almost disappeared in the Glas35 group of patients, particularly for the HF and LF bands. The third issue was the appearance of a significant peak in the VHF range (0.4-0.6 Hz), particularly evident in the Glas68 group, and only slightly evident in the Glas35 group. As can be observed (see Figure 5) the standard error limits of the mean values of the spectra in the three groups were very near to the values of the grand mean averages.

\section{Hilbert marginal spectra}

As the values of the PSD were extremely low in some patients, particularly in the Glas35 group, it was considered necessary to establish a limitation for the graphical representation of the individual HMS. For those cases, the upper value for the Y-axis of the spectrograms was fixed to a value that was 3 standard deviations below the mean values of the maximal peak power spectral density calculated for the HMS of the subjects in the control healthy group. That value corresponded to 2,600 $\mathrm{ms}^{2}$. All HMS of the patients of Glas35 group are shown in Figure 6, including in each spectral diagram some additional data of their physiological vital indices. From the 24 patients in this group, 9 patients $(37.5 \%)$, all of them with values Glasgow coma scale score scale of 3, presented PSD values below the previously described limit (see Figure 6).

The visual inspection of the HMS of the comatose patients showed the presence of peaks in the VHF range considered in this study $(0.4-0.6 \mathrm{~Hz})$ in 4 patients $(17.4 \%)$ of the Glas68 group, and in 6 patients (25\%) of the Glas35 group (Fig. 6). Considering the whole group of patients, the observed proportion was of 10 in 47 patients $(21.2 \%)$.

As the most affected HRV indices and vital physiological indices, including the HMS, were detected in the patients with GCS 3, a detailed particular analysis was carried out in this subgroup of patients. The results are presented in Table 6 . 
Attending to some quantitative and qualitative criteria of the Hilbert marginal spectra in the patients in coma, five patterns were identified: pattern A was ascribed to spectra that showed an identifiable PSD, but limited to an isolated peak of the VLF, the HF or the VHF band, the B pattern included spectra with markedly reduced values of PSD $\left(<1,000 \mathrm{~ms}^{2}\right)$, without evidence of relevant peaks, assessed by the Fisher's g-Statistic, the C pattern included spectra with reduced values of PSD $\left(1,000-6,000 \mathrm{~ms}^{2}\right)$ with identifiable peaks in the VLF and LF bands, and the D pattern was considered when the PSD values were from 6,000-12,000 $\mathrm{ms}^{2}$ with identifiable peaks in different bands, and finally, an E pattern was defined when the PSD was over $12,000 \mathrm{~ms}^{2}$ with well-defined peaks. In the Glas68 group the patterns showed the following distribution: Pattern-A was found in 2 patients $(8.7 \%)$, Pattern-C in 8 (34.8\%), Pattern-D in 1 (4.3\%), and Pattern-E in $12(52.2 \%)$. The pattern B was not observed in the Glas68 group. In the Glas35 group the observed distribution was: Pattern-A was observed in 7 patients (29.2\%), Pattern-B in 5 (20.8\%), Pattern-C in 7 (29.2\%), Pattern-D in 4 (16.6\%), and Pattern E in 1 patient (4.2\%).

This classification, applied to the subgroup of patients with GCS $=3$, showed that Pattern A was found in 6 patients $(37.5 \%)$, the pattern B was found in 5 patients $(31.2 \%)$, and the patterns $\mathrm{C}$ and $\mathrm{D}$ were detected in $2(12.5 \%)$ and 3 patients (18.8\%), respectively (see Table 6, and Figure 6).

\section{Autonomic assessment of patients in deep coma}

Considering the clinical signs, and the observed values of the vital indices observed during the recording experimental sessions (see Table 6), the ANS functional state was assessed as steady, increments or decrements of sympathetic or parasympathetic predominance, and autonomic dysregulations (ADys). A type-A autonomic dysregulation 
was defined when the values of the systolic blood pressure (SBP) were $\leq 80 \mathrm{mmHg}$ and the heart rate was over 100 beats/min. A type-B was defined when the SBP was over $150 \mathrm{mmHg}$ and the heart rate below 50 beats/min. In the group of 16 patients with GCS 3, the ANS assessment resulted steady in only one patient $(6.2 \%)$, an increment of the sympathetic influences was observed in $9(62.6 \%)$, a decrement of sympathetic influences in $1(6.2 \%)$, a type-A autonomic dysregulation was detected in 3 patients $(18.8 \%)$, and a type-B autonomic dysregulation in 1 patient (6.2\%) (see Table 6). In this subgroup of 16 patients with a GCS $=3,25 \%$ showed a definite autonomic dysregulation $(\mathrm{A}$ or $\mathrm{B})$.

Some degree of association was observed between the presences of the described type-A autonomic dysregulation with the pattern B of the HMS (see Table 6). From the 5 patients with HMS pattern B, 3 of them $(60 \%)$ presented that type of autonomic dysregulation.

\section{Mortality}

The mortality at 6 months in the group of patients was $42.55 \%$ (20 patients died and 27 survived). The comparison of clinical and HRV variables between survivors and nonsurvivors did not show significant differences for the clinical variables (see Table 7). HRV indices calculated in the time domain demonstrated significant differences for the MRRi (higher values in survivors indicating a lower heart rate), SDRR (higher global variability in survivors), and nDRRs (higher number in survivors). The HRV index of complexity ShaEn was higher in survivors. All the spectral indices estimating absolute values of the PSD showed significant higher values in survivors, except for the P-VHF. PSD values, expressed in normalized units, showed significant higher values in survivors for the nu-VLF, and nuLF indices, while for the nu-VHF index the values in non-survivors resulted significantly 
higher. We did not find significant differences for the nu-HF, the $\mathrm{LF} / \mathrm{HF}$, and for the indices of central frequencies cf-IMF-2, cf-IMF-3, and cf-IMF-4 (see Table 7). All the patients that showed a pattern A or B of the HRV spectra in this study (13) died.

\section{Logistic regression analysis}

The univariate logistic regression analysis showed significant results for only 8 of the $22(36.4 \%)$ HRV indices included in this study: nu-VHF ( $\mathrm{p}=0.0001)$, P-VLF $(\mathrm{p}=0.001)$, PLF $(p=0.002)$, P-HF $(p=0.004)$, nu-VLF $(p=0.02)$, ShaEn $(p=0.002)$, SDRR $(p=0.03)$, and nDRRs $(p=0.008)$. The GCS $(p=0.329)$, the patient's age $(p=0.427)$, the systolic blood pressure $(\mathrm{p}=0.411)$, the diastolic blood pressure $(\mathrm{p}=0.248)$, and the respiratory rate $(\mathrm{p}=0.938)$ did not show significant prediction values.

When the nu-VHF index was dichotomized at value $10 \%(<10 \%=0$ and $>10 \%=1)$ considering the results of the receiver operating characteristic (ROC) analysis and the area under the curve (AUC) of this index (0.922 and standard error 0.047), it showed a sensitivity of $95.0 \%$, specificity of $88.88 \%$, positive predictive value of $86.36 \%$, negative predictive value of $96.0 \%$, and an overall efficiency (measured as total of correct classifications / total of patients) of $91.49 \%$ for predicting death.

A "mortality score" (MS) was calculated using the forward stepwise multivariate logistic regression analysis, using as covariates all the studied HRV indices (with adjusted values when required). The details of the analysis are included in Table 8 , and the model was described by the following equation:

$$
M S=9.378+0.558 *(n u-V H F)-2.164 *(P-L F)+1.585 *(P-V L F)
$$


The first step of the stepwise forward multiple logistic regression analysis extracted the nu-VHF index reaching the model an accuracy of $93.6 \%$ of correct classifications; the second step added the P-LF index while the model maintained an accuracy of $93.6 \%$; the third and last step added the P-VLF index reaching the model an accuracy of $95.7 \%$. The goodness-of-fit of the model was assessed with the Hosmer and Lemeshow test $(0.964, \mathrm{p}=$ 0.995), the $-2 \log$ likelihood value (11.318), the Cox \& Snell R square (0.682), and the Nagelkere R square (0.909), all of them showing a good fit. The model described by the equation (9) detected 22 correct deaths and 23 survivals, one patient was incorrectly classified as survivor, and one patient as non-survivor. The sensitivity was $95.65 \%$, the specificity was $95.83 \%$, the positive predictive value was $95.65 \%$, the negative predictive value was $95.83 \%$, and the overall efficiency (accuracy) of the model was $95.74 \%$.

The ROC curves for the values obtained using the equation (9) showed an AUC of 0.939 indicating good efficiency (see Figure 7). The ROC curves of other clinical variables and HRV indices were also obtained. The GCS showed an AUC of 0.648, and the HR index a value of 0.649 , showing both low efficiency, while other HRV indices showed higher accuracy, but lower than those obtained for the model: $\mathrm{SD}=0.824$, P-HF curves $=0.842$, and ShaEn $=0.857($ see Figure 7$)$.

\section{Discussion}

The most outstanding result of this study was the reduction of HRV observed in the patients in coma, which showed a progressive trend associated with deepening of coma, assessed by the GCS and the high effectivity of HRV indices for predicting mortality in patients in coma. Reduced HRV has been previously observed and reported by us [13, 15, 16] and by many other authors that have investigated patients in coma with brain lesions of 
different etiologies $[6,7,10-12,14,18,21,26]$. Several studies have demonstrated the potential utility of HRV as an indicator of mortality in intensive care unit patients [24, 25, 28-32], and also as an indicator of prediction of lifesaving interventions in patients with trauma [22, 33-37]. However, to our knowledge, this study is the first reporting this issue by applying a novel method for the analysis of HRV indices, the so called Hilbert-Huang method, that has been developed for the digital processing of signals that contain nonGaussian, nonlinear or non-stationary processes, as is the case of the cardiac R-R tachograms, from which are derived the HRV indices [63, 68, 69, 74, 91-93]

Significant differences have been found of HRV indices between survivors and nonsurvivors in several studies. The LF/HF index resulted reduced in non-survivors $[17,18,23$, 24, 26]. Estimations of the PSD in the VLF band were found reduced in non-survivors in two studies [18, 23], while were found increased in other report [20]. Absolute values of PSD in the LF band were reduced in non-survivors $[18,20]$, and recently also for the HF band [26]. Reduced values in non-survivors have been reported for the PSD of the LF band expressed in normalized units [24]. Time domain RMSSD index was reported reduced in non-survivors in one report [19]. In our study were confirmed some of those findings, but more HRV indices showed significant differences between survivors and non-survivors, including time domain calculated HRV indices (SDRRs and nDRRs), an informational complexity index (ShaEn), and several frequency domain HRV indices expressed in absolute values (P-VLF, P-LF, P-Tot), or in normalized units (nu-VLF, nu-LF). The nu-VHF index showed significant higher values in non-survivors. In this study no significant differences were found between survivors and non-survivors for the GCS, a typical indicator of hemispheric function [18], the age, the blood pressure values and the respiratory rate. In other 
studies there have been found differences in the GCS between survivors and non-survivors $[18,20,22-24,26]$. This can be explained because in our study all patients had a GCS $<=8$, while other studies have included patients with unlimited GCS scores. Nevertheless, the fact that in some studies at least one standard vital sign (e.g. GCS, age, blood pressure) also distinguished between two groups of patients (e.g. survived versus non-survived, lifesaving versus non-lifesaving interventions) has been argued [37] that can cause that the added values of HRV indices may become unclear. So, the absence of significant differences between survivors and non-survivors found in our study for the GCS, age, blood pressure, and respiratory rate resulted in an advantage.

Univariate logistic regression analysis showed that several HRV indices showed a positive significant value for predicting mortality in our study, albeit only three of them were later included in the model using the statistic criteria for the multiple logistic regression analysis (MLRA), but none of the possible confounding variables considered in this study showed significant values on the univariate tests of logistic regression.

Prediction of mortality in acute severe stroke patients using MLRA including ventilation, vasopressor use, eye-opening GCS score and nu-LF index showed for the model a positive predictive value of $81.8 \%$, and specificity of $78.6 \%$ [20]. Another model of mortality prediction including the P-VLF, the P-HF, and patient's age obtained through MLRA showed a sensitivity of $88.2 \%$, specificity of $81.4 \%$, and $80.4 \%$ efficiency. The AUC for the ROC curve of the model was 0.845 [23]. A recent study including intracranial pressure, pressure reactivity index (derived from invasively recorded blood pressure measurements), GCS, patient's age, HRV indices, and baroreflex sensitivity, in a model obtained with MLRA to predict mortality in TBI patients, showed an AUC on the ROC curve 
of 0.844 [26]. In our study the model obtained by MLRA included the nu-VHF, the P-LF, and the P-VLF HRV indices, and showed a sensitivity of $95.65 \%$, a specificity of $95.83 \%$, a positive predictive value of $95.65 \%$, and an overall efficiency of $95.74 \%$. The AUC of the ROC curve was 0.939. Meanwhile, it is noteworthy that our model did not include demographic or other physiological variables, out of the HRV indices to predict mortality.

These results are better than those previously reported, and some associated issues may be implicated. First, it has been analysed that HRV has had limited application as a screening tool because its sensitivity for detecting an outcome in patients with brain injuries is usually high, but its specificity is usually low $[19,21]$. Confounding factors have been implicated in the low specificity and efficiency of HRV indices in predicting different outcomes in those patients $[19,21,23,37]$. In our study, as in other reports in this field, the problem of confounding factors $(\mathrm{CF})$ was present, as was evidenced by the correlation analysis. The statistical approach used in this study to cope with the CF generally followed the method used by [88] in a study with epileptic patients. This procedure, adapted to our particular analysis, seems effective and recommendable, and allowed a probabilistic means to assess the real significant differences of HRV indices between groups, making possible a more realistic clinical and physiological assessment. Second, the distortion of HRV indices produced by the mathematical relationship between the heart rate and HRV indices described in different reports [40,41, 94-98] can modify the predicting potentialities of HRV indices, although it has only been acknowledged by few authors that have studied the potentialities of HRV indices for predicting outcomes in patients with brain injury [37]. In the current study those deleterious influences were avoided correspondingly. Third, another issue to be considered is the effect of nonlinear and non-stationary processes that have necessarily to be 
present in these critically ill patients [22, 23, 33], and that can be overcome using appropriate methods for the analysis of HRV indices, as those used in this study. Fourth and finally, the inclusion for the spectral analysis of HRV indices of the very high frequency range $(0.4-0.6$ $\mathrm{Hz}$ ), that has been not extensively studied, but that has shown evidences of pathophysiologic interest in the last years $[70,71,99-101]$. All these issues were considered in our study and possibly are associated to better results, so we recommend them for later use in this field. Our results also confirm that the spectral HRV indices show a better prediction for mortality or other outcomes as others have noted [20]. Nevertheless, the patients included in our study showed different etiologies, but we consider that in patients in coma with the same etiology, as in patients with TBI, the results should be even better. It is also important also to emphasize that comparisons of the results obtained by different authors for HRV indices is compromised by the use of non-standardised methods. To show at least one of these problems: HRV indices have been calculated in different studies from electrocardiograms (ECG) recorded during 15 minutes [23], 5 minutes [17, 18, 20, 21, 26, 29, 102], 7 minutes [16], 2 minutes [24], 288 seconds [14], 600 seconds [103], 200 consecutive beats [33, 34, 36], 800 consecutive heart beats [37], or not clearly specified [12, 19, 104]. Notwithstanding these methodological differences (and many others not detailed here) between studies, HRV indices have shown their efficiency to predict different outcomes in patients with brain injuries.

\section{Methodological considerations}

Before continuing the discussion of the HRV findings, important methodological considerations should be considered. In this study we obtained the original ECG recordings using a sampling frequency (SF) of $200 \mathrm{~Hz}$. To reduce the quantisation errors while measuring the R-R intervals, the ECG was interpolated to achieve a SF of $1000 \mathrm{~Hz}$. In a 
previous report [16] we did not use this procedure, but now we recommend it, because the measures of HRV are very low in patients in coma, and it is possible that the spectral indices could be affected in some degree [105]. This situation is frequently found in the medical practice, because the most extended conventional commercial equipment for EEG recording, generally uses a SF of $200-250 \mathrm{~Hz}$, and the ECG that is used later for HRV analysis is generally simultaneously recorded with the EEG. The first investigations of the effect of the original SF of the ECG recording on spectral HRV indices appeared when the ECG recorders for Holter monitoring were developed with a SF of $128 \mathrm{~Hz}$, that were the main source for ulterior analysis of HRV [106]. These authors concluded that the SF of $128 \mathrm{~Hz}$ did not produce deleterious effects on HRV indices. This problem has been renewed in the last few years, and it has been conclusively shown [107] that it is not necessary to use some 'recommended' values of SF of the ECG (500-1000 Hz) for HRV analysis, when the original SF of the ECG recording has been over $125 \mathrm{~Hz}$, and even better, when these signals are submitted to a cubic spline interpolation procedure that was originally described by [108], and that we used in this investigation. Resampling the originally recorded ECG cannot be mistaken with the resampling procedure applied to the R-R tachograms. As the originally measured consecutive R-R interval values are ordinal series, they need to be transformed into temporal series for spectral analysis, when using different spectral parametric and nonparametric methods. The most frequently used transformation for the R-R tachograms is the resampling method using an interpolation procedure [1]. There is another approach consisting in the use of the Lomb-Scargle method for the spectral analysis of the original tachogram $[109,110]$, but the spectra obtained using this method show some overestimation of the high frequencies of HRV [110]. Other Fourier methods, and also the Lomb-Scargle procedure, rely on considering the R-R tachogram as stationary, and that the implicated 
physiological processes are linear. The SF for the interpolation procedure has to be sufficiently high that the Nyquist frequency of the spectrum is not within the frequency range of interest [1]. This frequency range is that of the mean heart frequency of the investigated subjects. The R-R intervals of the tachogram only gives a unique representation of a signal if we assume that this is band-limited to the frequency inverse of the mean heart period [111]. It has been shown that the SF of the tachogram resampling should be at least twice the maximum frequency of the heart frequency [112]. Clifford and colleagues [112] recommended using at least $7 \mathrm{~Hz}$, corresponding to a maximal heart frequency of 210 beats/min. As the mean heart frequency observed in our patients in coma was approximately around 100 beats/min, corresponding to $1.66 \mathrm{~Hz}$, the Nyquist frequency associated to this value was $0.83 \mathrm{~Hz}$, and for this reason we selected a SF of $4 \mathrm{~Hz}$ for resampling the tachograms in this study. Besides, this fact allowed us to fix the limit of $0.6 \mathrm{~Hz}$ as the upper valid frequency of the HRV, because it was fairly lower than the Nyquist frequency of $0.83 \mathrm{~Hz}$.

\section{Autonomic impairment related with the deepening of coma}

According to our results, patients in coma showed a decrement of parasympathetic influences from the ANS, demonstrated by the reduced values of the time domain calculated indices (SDNN, RMSSD, W, nDRRs, and NRatio), and the spectral indices associated with the HF band (P-HF). The RMSSD and the P-HF indices are considered to be markers of the parasympathethic activity. Concomitantly, an increase of the sympathetic influences was demonstrated by the increment of the spectral values of the LF band indices, mainly expressed in absolute PSD values (P-LF). Moreover, it was also evident an increase of the spectral indices of the VLF band, expressed mainly in normalized units (nu-VHF), that have been associated with the activity of the thermoregulatory system, the renin-angiotensin 
system, and the vasopressor arm of the sympathetic ANS. The Shannon entropy index, a complexity indicator, showed a marked reduction mainly in the group of patients with GCS values from 3 to 5. The increment of the MRRi (the reciprocal value of the heart frequency), also points to incremented sympathetic ANS influences. These results show some agreement with those in a previous report [16], but in that paper the number of patients was lower, and the possible effects of confounding factors were not considered as in this investigation. Other authors have also reported a similar trend of changes for the autonomic control in patients in coma $[17,21,23]$.

The frequencies associated with the IMFs extracted from the resampled R-R tachograms using the empirical mode decomposition method, and corresponding to frequencies of the HF band (cf-IMF-2 and cf-IMF-3), showed significant increments for both groups of patients in coma, demonstrating that in the HF band the changes are not limited to reductions of the PSD values, but also to a displacement (sliding) to higher values of the mean frequencies of the band. A similar increment was observed for the mean frequencies of the IMF-3, with values in the range of the LF band (see Table 4). These frequency displacements in different HRV bands to higher values have not been previously reported and can be related with the autonomic disturbances produced in the ANS of the patients in coma that deserves further study.

\section{Patterns of HMS in patients in coma}

The pattern classification described in this study, considering some quantitative and qualitative characteristics of the HMS of the patients in coma, allowed us to find clear differences of the observed proportions of the spectral patterns between the two groups of patients. Patterns A and B may be considered the most abnormal, because they represent an 
extreme reduction, or even absence of autonomic influences from the autonomic nervous system default network, and particularly from the lower brain stem centres [113]. The B pattern was only detected in patients with a GCS $=3$, while the A pattern was only detected in two patients of the Glas68 group (8.7\%), but in 5 patients $(20.8 \%)$ of the Glas 35 group. In our study all patients showing A or B patterns died, but as this feature is a so called dummy variable we did not considered it for the logistic regression analysis, but it could be very helpful for future studies, with a higher sample of patients.

\section{Autonomic dysregulation of patients in deep coma}

In this investigation we found in the 16 patients with $\mathrm{GCS}=3$, that they could be included into different clusters attending to clinical, autonomic, physiological vital indices, and spectral patterns, showing the limitations of the GCS scale when patients arrive to the lower score limit of this classical useful clinical scale. Although the number of patients was relatively low (16) we could distinguish four subgroups of patients, using the criteria that were detailed in Table 6. The presence of severe autonomic hemodynamic disturbances, known as dysautonomia, in some of these patients did not show the definite signs that have been described by some authors [11, 114-116]. So, we used the term autonomic dysregulation, and could find increments or decrements of the sympathetic or parasympathetic influences assessed by the clinical assessment, the characteristics of the HRV, and other physiological vital indices, particularly the blood pressure. We described two types of dysregulations associated with the dissociation between indices of the integral index of the cardiovascular autonomic regulation, the heart frequency, and the measures of blood pressure, and we found some degree of relationship with particular patterns of the observed HMS. In a previous report [16] we noted in a very low sample of patients in coma 
with GCS $=3$, the presence of tachycardia while others showed bradycardia. In this study we have found that these cardiovascular signs can be associated with a paradoxical behaviour of the blood pressure values, that should be further explored considering that some authors have emphasized the presence of severe autonomic disturbances in patients during deep coma, preceding brain death [117] and that vasopressor control is severely affected in recently diagnosed brain dead patients [118]. The definite autonomic disturbances evidenced by HRV indices of patients in coma, and particularly the reduction of the variability of the R-R tachograms, that can be detected in cases with relatively high values of the GCS (7 and 8) cannot be explained (in our opinion) on the basis of disturbances of the autonomic centres of the lower brain stem. These structures may play a crucial role in the deep coma (GCS 3-5), and in quasi brain dead patients, but the higher centres of the autonomic control in the brain must be implicated in those stages of coma (GCS 7-8) during which there is some degree of functional and anatomical integrity of those structures that conform the central autonomic network of the forebrain: the insular cortex, the anterior cingulate cortex, the amygdala, and the hypothalamus [113]. Morris et.al [29] coined the term "cardiac uncoupling" associated to the reduction of HRV observed in trauma patients, that proved to be a predictor of mortality. They considered that this reduced HRV should be considered as a new biomarker reflecting the loss of commands and control of the heart. Since 1996 Korpelainen et al. [119] had noted that the loss of total power of HRV may be anatomically related and be possibly a marker of brainstem damage. Our results confirm those criteria, and show that HRV indices can be used successfully for monitoring the integrity of structures of the lower segments of the brainstem, that control the cardiovascular regulation, particularly in patients in the ICU.

\section{Very high frequency oscillations of patients in coma}


The progressive intense reduction of the HRV in the two groups of patients in coma was also clearly evident using the method of the grand mean spectral averages. This method showed that peaks of activity were present in the frequency range from 0.4 to $0.6 \mathrm{~Hz}$, that were more visually evident in the Glas68 patient's group, corresponding to the very high frequency range recently reported also in other studies [70, 71]. These authors reported a frequency range extension of spectral analysis of pulse rate variability, a surrogate measurement of HRV, based on the Hilbert-Huang method, from 0.4 to $0.9 \mathrm{~Hz}$ in healthy subjects. They showed also that in resting conditions the spectral values of the VHF, extracted from the R-R tachograms, represented approximately $6.2 \%$ of the total spectral PSD in this range. A careful bibliographic search carried out using different sources (Pubmed, Scopus, Medline, etc.), allowed us to find that the first reports about spectral components in this VHF band of the HRV corresponded to authors that were studying the process of re-innervation after cardiac transplantation [120, 121]. Mateo et al. reported findings in the VHF spectrum in cardiac ischemic patients [122, 123], that were useful in differentiating between ischemic and non-ischemic patients. They also found that the VHF and VLF band indices of HRV resulted to be the most relevant in patients with coronary ischemic disease during exercise [124]. Later, other authors $[125,126]$ demonstrated that the VHF peaks were not artifactual, and that its presence could serve as a diagnostic test for vagal denervation, and even classified the VHF peaks into two types associated to possible different pathophysiologic significance [127]. Other authors have reported differences of VHF spectral measures between patients with cardiologic disturbances and healthy controls [99, 100]. Recently [101] we have shown, using three spectral methods, including the HilbertHuang method, the presence of VHF activity in healthy humans in the range from 0.4 to 0.6 $\mathrm{Hz}$, and the significant increment of the PSD expressed in normalized units in this frequency 
band, in patients of type-2 spinocerebelar ataxia (SCA-2) with positive signs of cardiac autonomic neuropathy, assessed with autonomic testing, with significant reduction of the vagal parasympathetic activity. However, this VHF activity was not observed in the form of peaks. In our study, the absolute values of PSD in this band showed significantly reduced values in both groups of patients, as was demonstrated for all the other classical HRV bands, but the values of the spectral VHF band, expressed in normalized units (\%), resulted significantly incremented in both groups of patients, and were significantly higher in the Glas35 group, compared with the Glas68 group. The values of the mean instantaneous frequencies of the IMF-2 component (cf-IMF-2), including the VHF range, showed a sliding movement to higher frequencies previously described for other bands. The presence of peaks in the VHF range considered for this study in limits from $0.4-0.6 \mathrm{~Hz}$ was detected in the HMS in 4 patients $(17.4 \%)$ of the Glas68 group, and in 6 patients $(25 \%)$ of the Glas35 group. Considering the whole group of patients, the observed proportion was of 10 in 47 patients (21.2\%). In other patients in coma the presence of activity in the VHF range was not observed in the form of peaks, but was detected in the quantitative analysis of the PSD of the spectra. The frequency of the appearance of peaks in the VHF range, considered from 0.4 to $1.0 \mathrm{~Hz}$, was reported by other authors in 9 recordings of 6 patients after some months of cardiac transplantation (CT), and not observed in 8 recordings from other 4 CT patients [125], and in 9 CT patients from 13 in other report [126]. It represents a higher frequency than that observed in our patients in coma (51\% vs. $21.2 \%)$. We have not found any other report in the already mentioned bibliographic databases, about the presence of VHF peaks in any other condition in humans. These changes, observed in the spectral indices of the VHF band, and the presence of VHF peaks, are to the best of our knowledge, the first report of this issue in patients in coma. 
We have also demonstrated for the first time that the increment of the PSD in the VHF frequency band expressed in normalized units, is a predictor of mortality in patients in coma. It results a very curious fact that for short duration calculated HRV indices, the more extreme bands of the spectra (VLF and VHF) be implicated in mortality risk of patients in coma. These two spectral bands have not received the same attention in the literature as the more classic LF and HF bands $(0.04-0.40 \mathrm{~Hz})$, but regarding the demonstrated predicting capacity of the VLF band to predict mortality and previous reports of our group and others $[18,20,23]$, these results demand a more detailed study of the VHF range of HRV, whose pathophysiological meaning is yet unclear. Our previous results in patients with SCA-2 and positive signs of cardiovascular neuropathy [101], and in this study, point to associate the increment of VHF activity expressed in normalized units (cutoff value $>10 \%$ ) as a physiological biomarker of the reduced, or even abolished influence, of the vagal influences to the sinoatrial node and a possible rearrangement of the intrinsic cardiac autonomic network system $[71,101,128]$.

\section{Conclusions}

In this study we have included a higher sample of patients in coma $(n=45)$ than in previous reports, and applied particular methods to cope with the presence of confounding factors and the effect of nonlinear and non-stationary processes associated with the critical state of the brain tissue during coma, and the results confirm the progressive reduction of HRV associated with deepening of coma reported in previous observations of our group and of other authors. Our results demonstrate that HRV is a reliable, non-expensive, and noninvasive method to assess the functional state of the ANS of patients in coma, and results particularly useful to evaluate the functional integrity of the nervous influences to the heart 
from the caudal autonomic centres of the brainstem, becoming an important physiological biomarker. Besides, HRV indices showed that can efficiently predict mortality in these patients. It is recommended that methodological and standardized procedures described in this study should be considered in later investigations to achieve more consistent results by other authors in this field. The demonstration of the predictive capacity of mortality of HRV indices on different spectral ranges, but particularly in the VHF range, shown for the first time in this study, deserve further studies to completely determine its pathophysiological meaning.

\section{Acknowledgments}

The authors' thanks go to the Laboratory of Signals and Nonlinear Dynamics of the University of Entre Ríos in the Republic of Argentina, especially to Marcelo A. Colominas and Profs. Gastón Schlotthauer and María E. Torres for their splendid work in the development and modifications of the CEEMDAN methods, with the corresponding $\begin{array}{llll}\text { implementations } & \text { in } & \text { Matlab } & \text { downloaded }\end{array}$ https://www.bioingenieria.edu.ar/grupos/ldnlys for use in the present study.

\section{Declaration of Interest}

The authors report no declarations of interest. 


\section{References}

1. Task_Force_of_ESC_and_NASPE. Heart rate variability. Standards of measurement, physiological interpretation, and clinical use. Task Force of the European Society of Cardiology and the North American Society of Pacing and Electrophysiology. Eur Heart J 1996;17(3):354-81.

2. Sosnowski M. Heart Rate Variability. In: Macfarlane PW, van Oosterom A, Pahlm O, Kligfield P, M. Janse M, J. C, editors. Comprehensive Electrocardiology. London: Springer-Verlag Limited; 2011. p. 1513-674.

3. Cygankiewicz I, Zareba W. Heart rate variability. Handbook of clinical neurology. 2013;117:379-93.

4. Kuusela T. Methodological Aspects of Heart Rate Variability Analysis. In: Kamath MV, Watanabe MA, Upton ARM, editors. Heart Rate Variability (HRV) Signal Analysis: Clinical Applications. I. First ed. Boca Raton, London, New York: CRC Press Taylor \& Francis Group; 2013. p. 9-46.

5. Riganello F, Cortese MD, Dolce G, Lucca LF, Sannita WG. The autonomic system functional state predicts responsiveness in DOC. Journal of neurotrauma. 2015;DOI: 10.1089/neu.2014.3539.

6. Shimomura C, Matsuzaka T, Koide E, Kinoshita S, Ono Y, Tsuji Y, Kawasaki C, Suzuki Y. Spectral analysis of heart rate variability in the dysfunction of the brainstem. No To Hattatsu. 1991;23(1):26-31.

7. Freitas J, Puig J, Rocha AP, Lago P, Teixeira J, Carvalho MJ, Costa O, de Freitas AF. Heart rate variability in brain death. Clin Auton Res 1996 Jun;6(3):141-6. 1996.

8. Conci F, Di Rienzo M, Castiglioni P. Blood pressure and heart rate variability and baroreflex sensitivity before and after brain death. Journal of neurology, neurosurgery, and psychiatry. 2001;71(5):621-31.

9. Machado C, Estevez M, Perez-Nellar J, Schiavi A. Residual vasomotor activity assessed by heart rate variability in a brain-dead case. BMJ case reports. 2015;DOI: 10.1136/bcr-2014-205677.

10. Hildebrandt H, Zieger A, Engel A, Fritz KW, Bussmann B. Differentiation of autonomic nervous activity in different stages of coma displayed by power spectrum analysis of heart rate variability. Eur Arch Psychiatry Clin Neurosci 1998;248(1):46-52. 1998.

11. Baguley IJ, Nott MT, Slewa-Younan S, Heriseanu RE, Perkes IE. Diagnosing dysautonomia after acute traumatic brain injury: evidence for overresponsiveness to afferent stimuli. Arch Phys Med Rehabil. 2009;90(4):580-6.

12. Vakilian AR, Iranmanesh F, Nadimi AE, Kahnali JA. Heart rate variability and QT dispersion study in brain death patients and comatose patients with normal brainstem function. Journal of the College of Physicians and Surgeons Pakistan. 2011;21(3):130-3. 
13. García OD, Machado C, Román JM, Cabrera A, Díaz-Comas L, Rivera B, Grave de Peralta R. In: Machado C, editor. Brain death (proceedings of the second international symposium on brain death). Development in neurology, vol. 9. Amsterdam: Elsevier; 1995. p. 191-200.1995.

14. Su CF, Kuo TB, Kuo JS, Lai HY, Chen HI. Sympathetic and parasympathetic activities evaluated by heart-rate variability in head injury of various severities. Clinical neurophysiology : official journal of the International Federation of Clinical Neurophysiology. 2005;116(6):1273-9.

15. Machado C, Garcia OD, Gutierrez J, Portela L, Garcia MC. Heart rate variability in comatose and brain-dead patients. Clinical neurophysiology : official journal of the International Federation of Clinical Neurophysiology. 2005;116(12):2859-60; author reply 60.

16. Machado-Ferrer Y, Estevez M, Machado C, Hernandez-Cruz A, Carrick FR, Leisman G, Melillo R, Defina P, Chinchilla M, Machado Y. Heart rate variability for assessing comatose patients with different Glasgow Coma Scale scores. Clinical neurophysiology : official journal of the International Federation of Clinical Neurophysiology. 2013;124(3):589-97.

17. Biswas AK, Scott WA, Sommerauer JF, Luckett PM. Heart rate variability after acute traumatic brain injury in children. Critical care medicine. 2000;28(12):3907-12.

18. Haji-Michael PG, Vincent JL, Degaute JP, van de Borne P. Power spectral analysis of cardiovascular variability in critically ill neurosurgical patients. Critical care medicine. 2000;28(7):2578-83.

19. Rapenne T, Moreau D, Lenfant F, Boggio V, Cottin Y, Freysz M. Could heart rate variability analysis become an early predictor of imminent brain death? A pilot study. Anesth Analg. 2000;91(2):329-36.

20. Gujjar AR, Sathyaprabha TN, Nagaraja D, Thennarasu K, Pradhan N. Heart rate variability and outcome in acute severe stroke: role of power spectral analysis. Neurocrit Care. 2004;1(3):347-53.

21. Proctor KG, Atapattu SA, Duncan RC. Heart rate variability index in trauma patients. J Trauma. 2007;63(1):33-43.

22. Cancio LC, Batchinsky AI, Salinas J, Kuusela T, Convertino VA, Wade CE, Holcomb JB. Heart-rate complexity for prediction of prehospital lifesaving interventions in trauma patients. J Trauma. 2008;65(4):813-9.

23. Ryan ML, Ogilvie MP, Pereira BM, Gomez-Rodriguez JC, Manning RJ, Vargas PA, Duncan RC, Proctor KG. Heart rate variability is an independent predictor of morbidity and mortality in hemodynamically stable trauma patients. J Trauma. 2011;70(6):1371-80.

24. Cooke WH, Salinas J, Convertino VA, Ludwig DA, Hinds D, Duke JH, Moore FA, Holcomb JB. Heart rate variability and its association with mortality in prehospital trauma patients. J Trauma. 2006;60(2):363-70. 
25. Batchinsky AI, Cancio LC, Salinas J, Kuusela T, Cooke WH, Wang JJ, Boehme M, Convertino VA, Holcomb JB. Prehospital loss of R-to-R interval complexity is associated with mortality in trauma patients. J Trauma. 2007;63(3):512-8.

26. Sykora M, Czosnyka M, Liu X, Donnelly J, Nasr N, Diedler J, Okoroafor F, Hutchinson P, Menon D, Smielewski P. Autonomic Impairment in Severe Traumatic Brain Injury: A Multimodal Neuromonitoring Study. Critical care medicine. 2016;44(6):1173:81.

27. Winchel RJ, Hoyt DB. Spectral analysis of heart rate variability in the ICU: A measure of autonomic function. . J Surg Res. 1996;63:11-6.

28. Winchell RJ, Hoyt DB. Analysis of heart-rate variability: a noninvasive predictor of death and poor outcome in patients with severe head injury. J Trauma. 1997;43(6):927-33.

29. Morris JA, Jr., Norris PR, Ozdas A, Waitman LR, Harrell FE, Jr., Williams AE, Cao H, Jenkins JM. Reduced heart rate variability: an indicator of cardiac uncoupling and diminished physiologic reserve in 1,425 trauma patients. J Trauma. 2006;60(6):1165-73.

30. Norris PR, Anderson SM, Jenkins JM, Williams AE, Morris JA, Jr. Heart rate multiscale entropy at three hours predicts hospital mortality in 3,154 trauma patients. Shock. 2008;30(1):17-22.

31. Norris PR, Ozdas A, Cao H, Williams AE, Harrell FE, Jenkins JM, Morris JA, Jr. Cardiac uncoupling and heart rate variability stratify ICU patients by mortality: a study of 2088 trauma patients. Ann Surg. 2006;243(6):804-12.

32. Norris PR, Stein PK, Morris JA, Jr. Reduced heart rate multiscale entropy predicts death in critical illness: a study of physiologic complexity in 285 trauma patients. Journal of critical care. 2008;23(3):399-405.

33. Mejaddam AY, Birkhan OA, Sideris AC, Van der Wilden GM, Imam AM, Hwabejire JO, Chang Y, Velmahos GC, Fagenholz PJ, Yeh DD, et al. Real-time heart rate entropy predicts the need for lifesaving interventions in trauma activation patients. The journal of trauma and acute care surgery. 2013;75(4):607-12.

34. Liu NT, Holcomb JB, Wade CE, Darrah MI, Salinas J. Utility of vital signs, heartrate variability and complexity, and machine learning for identifying the need for life-saving interventions in trauma patients. Shock. 2014;DOI: 10.1097/SHK.0000000000000186.

35. Liu NT, Holcomb JB, Wade CE, Salinas J. Improving the Prediction of Mortality and the Need for Life-Saving Interventions in Trauma Patients Using Standard Vital Signs With Heart-Rate Variability and Complexity. Shock. 2015;DOI: 10.1097/SHK.0000000000000356.

36. Naraghi L, Mejaddam AY, Birkhan OA, Chang Y, Cropano CM, Mesar T, Larentzakis A, Peev M, Sideris AC, Van der Wilden GM, et al. Sample entropy predicts lifesaving interventions in trauma patients with normal vital signs. Journal of critical care. 2015;30(4):705-10.

37. Rickards CA, Ryan KL, Ludwig DA, Convertino VA. Is heart period variability associated with the administration of lifesaving interventions in individual prehospital trauma patients with normal standard vital signs? Critical care medicine. 2010;38(8):1666-73. 
38. Antelmi I, de Paula RS, Shinzato AR, Peres CA, Mansur AJ, Grupi CJ. Influence of age, gender, body mass index, and functional capacity on heart rate variability in a cohort of subjects without heart disease. Am J Cardiol. 2004;93(3):381-5.

39. Fathizadeh P, Shoemaker WC, Wo CC, Colombo J. Autonomic activity in trauma patients based on variability of heart rate and respiratory rate. Critical care medicine. 2004;32(6):1300-5.

40. Nieminen T, Kahonen M, Koobi T, Nikus K, Viik J. Heart rate variability is dependent on the level of heart rate. Am Heart J. 2007;154(1):e13 DOI:0.1016/j.ahj.2007.04.050.

41. Monfredi O, Lyashkov AE, Johnsen AB, Inada S, Schneider H, Wang R, Nirmalan M, Wisloff U, Maltsev VA, Lakatta EG, et al. Biophysical Characterization of the Underappreciated and Important Relationship Between Heart Rate Variability and Heart Rate. Hypertension 2014;DOI: 10.1161/HYPERTENSIONAHA.114.03782.

42. Akselrod S, Gordon D, Ubel FA, Shannon DC, Berger AC, Cohen RJ. Power spectrum analysis of heart rate fluctuation: a quantitative probe of beat-to-beat cardiovascular control. Science. 1981;213(4504):220-2.

43. Sassi R, Cerutti S, Lombardi F, Malik M, Huikuri HV, Peng CK, Schmidt G, Yamamoto Y, Gorenek B, Lip GY, et al. Advances in heart rate variability signal analysis: joint position statement by the e-Cardiology ESC Working Group and the European Heart Rhythm Association co-endorsed by the Asia Pacific Heart Rhythm Society. Europace : European pacing, arrhythmias, and cardiac electrophysiology : journal of the working groups on cardiac pacing, arrhythmias, and cardiac cellular electrophysiology of the European Society of Cardiology. 2015;17(9):1341-53.

44. Huang NE, Shen Z, Long SR, Wu MC, Shih HH, Zheng Q, Yen N, Tung CC, Liu HH. The empirical mode decomposition and the Hilbert spectrum for nonlinear and nonstationary time series analysis. Proc R Soc Lond. 1998;454:903-95.

45. Flandrin P, Rilling G, Goncalves P. Empirical Mode Decomposition as a Filter Bank. IEEE Signal Processing Letters. 2004;11(2):112-4.

46. Huang NE, Young V, Lo MT, Wang YH, Peng CK, Chen X, Wang G, Deng J, Wu $\mathrm{Z}$. The uniqueness of the instantaneous frequency based on intrinsic mode function. Adv Adapt Data Anal. 2013;5(3):1350011-1-14.

47. Colominas MA, Schlotthauer G, Torres ME. Improved complete ensemble EMD: A suitable tool for biomedical signal processing. Biomedical Signal Processing and Control. 2014;14:19-29.

48. Huang NE, Hu K, Yang ACC, Chang HC, Jia D, Liang WK, Yeh JR, Kao CL, Juan $\mathrm{CH}$, Peng $\mathrm{CK}$, et al. On Holo-Hilbert spectral analysis: a full informational spectral representation for nonlinear and non-stationary data. Phil Trans R Soc A. 2016;374: 20150206.

49. Li X, Li D, Liang Z, Voss LJ, Sleigh JW. Analysis of depth of anesthesia with HilbertHuang spectral entropy. Clinical neurophysiology : official journal of the International Federation of Clinical Neurophysiology. 2008;119(11):2465-75. 
50. Hsu YF, Liao KK, Lee PL, Tsai YA, Yeh CL, Lai KL, Huang YZ, Lin YY, Lee IH. Intermittent theta burst stimulation over primary motor cortex enhances movement-related beta synchronisation. Clinical neurophysiology : official journal of the International Federation of Clinical Neurophysiology. 2011;122(11):2260-7.

51. Zheng Y, Wang G, Li K, Bao G, Wang J. Epileptic seizure prediction using phase synchronization based on bivariate empirical mode decomposition. Clinical neurophysiology : official journal of the International Federation of Clinical Neurophysiology. 2014;125(6):1104-11.

52. Zhang Y, Ji X, Zhang S. An approach to EEG-based emotion recognition using combined feature extraction method. Neuroscience letters. 2016;633:152-7.

53. Amo C, de Santiago L, Barea R, Lopez-Dorado A, Boquete L. Analysis of GammaBand Activity from Human EEG Using Empirical Mode Decomposition. Sensors. 2017;17(5).

54. Liu Q, Chen YF, Fan SZ, Abbod MF, Shieh JS. Improved spectrum analysis in EEG for measure of depth of anesthesia based on phase-rectified signal averaging. Physiological measurement. 2017;38(2):116-38.

55. Salisbury JI, Sun Y. Assessment of chaotic parameters in nonstationary electrocardiograms by use of empirical mode decomposition. Annals of biomedical engineering. 2004;32(10):1348-54.

56. Huang Z, Chen Y, Pan M. Time-frequency characterization of atrial fibrillation from surface ECG based on Hilbert-Huang transform. Journal of medical engineering \& technology. 2007;31(5):381-9.

57. Corthout J, Van Huffel S, Mendez MO, Bianchi AM, Penzel T, Cerutti S. Automatic screening of Obstructive Sleep Apnea from the ECG based on Empirical Mode Decomposition and wavelet analysis. Conference proceedings : Annual International Conference of the IEEE Engineering in Medicine and Biology Society IEEE Engineering in Medicine and Biology Society Annual Conference. 2008;2008:3608-11.

58. Acharya UR, Faust O, Sree V, Swapna G, Martis RJ, Kadri NA, Suri JS. Linear and nonlinear analysis of normal and CAD-affected heart rate signals. Computer methods and programs in biomedicine. 2014;113(1):55-68.

59. Mert A. ECG feature extraction based on the bandwidth properties of variational mode decomposition. Physiological measurement. 2016;37(4):530-43.

60. Zheng J, Wang W, Zhang Z, Wu D, Wu H, Peng CK. A robust approach for ECGbased analysis of cardiopulmonary coupling. Medical engineering \& physics. 2016;38(7):671-8.

61. Motin MA, Karmakar C, Palaniswami M. Ensemble Empirical Mode Decomposition with Principal Component Analysis: A Novel Approach for Extracting Respiratory Rate and Heart Rate from Photoplethysmographic Signal. IEEE journal of biomedical and health informatics. 2017;DOI: 10.1109/JBHI.2017.2679108.

62. Rajesh K, Dhuli R. Classification of ECG heartbeats using nonlinear decomposition methods and support vector machine. Computers in biology and medicine. 2017;87:271-84. 
63. Souza Neto EP, Custaud MA, Cejka JC, Abry P, Frutoso J, Gharib C, Flandrin P. Assessment of cardiovascular autonomic control by the empirical mode decomposition. Methods of information in medicine. 2004;43(1):60-5.

64. Maestri R, Pinna GD, Balocchi R, D'Addio G, Ferrario M, Porta A, Sassi R, Signorini MG, La Rovere MT. Clinical correlates of non-linear indices of heart rate variability in chronic heart failure patients. Biomedizinische Technik Biomedical engineering. 2006;51(4):220-3.

65. Maestri R, Pinna GD, Porta A, Balocchi R, Sassi R, Signorini MG, Dudziak M, Raczak G. Assessing nonlinear properties of heart rate variability from short-term recordings: are these measurements reliable? Physiological measurement. 2007;28(9):1067-77.

66. Maestri R, Pinna GD, Accardo A, Allegrini P, Balocchi R, D'Addio G, Ferrario M, Menicucci D, Porta A, Sassi R, et al. Nonlinear indices of heart rate variability in chronic heart failure patients: redundancy and comparative clinical value. Journal of cardiovascular electrophysiology. 2007;18(4):425-33.

67. Shafqat K, Pal SK, Kumari S, Kyriacou PA. Empirical mode decomposition (EMD) analysis of HRV data from locally anesthetized patients. Conference proceedings : Annual International Conference of the IEEE Engineering in Medicine and Biology Society IEEE Engineering in Medicine and Biology Society Annual Conference. 2009;2009:2244-7.

68. Ebrahimi F, Setarehdan SK, Ayala-Moyeda J, Nazeran H. Automatic sleep staging using empirical mode decomposition, discrete wavelet transform, time-domain, and nonlinear dynamics features of heart rate variability signals. Computer methods and programs in biomedicine. 2013;112(1):47-57.

69. Yeh JR, Peng CK, Lo MT, Yeh CH, Chen SC, Wang CY, Lee PL, Kang JH. Investigating the interaction between heart rate variability and sleep EEG using nonlinear algorithms. Journal of neuroscience methods. 2013;219(2):233-9.

70. Chang CC, Hsiao TC, Hsu HY. Frequency range extension of spectral analysis of pulse rate variability based on Hilbert-Huang transform. Medical \& biological engineering \& computing. 2014;52:343-51.

71. Chang CC, Hsu HY, Hsiao TC. The interpretation of very high frequency band of instantaneous pulse rate variability during paced respiration. Biomedical engineering online. 2014;13(1):46 DOI:10.1186/475-925X-13-46.

72. Mohebbi M, Ghassemian H. Predicting termination of paroxysmal atrial fibrillation using empirical mode decomposition of the atrial activity and statistical features of the heart rate variability. Medical \& biological engineering \& computing. 2014;52(5):415-27.

73. Schiecke K, Wacker M, Benninger F, Feucht M, Leistritz L, Witte H. Advantages of signal-adaptive approaches for the nonlinear, time-variant analysis of heart rate variability of children with temporal lobe epilepsy. Conference proceedings : Annual International Conference of the IEEE Engineering in Medicine and Biology Society IEEE Engineering in Medicine and Biology Society Annual Conference. 2014;2014:6377-80.

74. Altan G, Kutlu Y, Allahverdi N. A new approach to early diagnosis of congestive heart failure disease by using Hilbert-Huang transform. Computer methods and programs in biomedicine. 2016;137:23-34. 
75. Gupta P, Sharma KK, Joshi SD. Fetal heart rate extraction from abdominal electrocardiograms through multivariate empirical mode decomposition. Computers in biology and medicine. 2016;68:121-36.

76. Lin YC, Lin YH, Lo MT, Peng CK, Huang NE, Yang CC, Kuo TB. Novel application of multi dynamic trend analysis as a sensitive tool for detecting the effects of aging and congestive heart failure on heart rate variability. Chaos. 2016;26(2):023109.

77. Bravi A, Longtin A, Seely AJ. Review and classification of variability analysis techniques with clinical applications. Biomedical engineering online. 2011;10:90.

78. Viola AU, Tobaldini E, Chellappa SL, Casali KR, Porta A, Montano N. Short-term complexity of cardiac autonomic control during sleep: REM as a potential risk factor for cardiovascular system in aging. PLoS One. 2011;6(4):e19002.

79. Clark MT, Rusin CG, Hudson JL, Lee H, Delos JB, Guin LE, Vergales BD, PagetBrown A, Kattwinkel J, Lake DE, et al. Breath-by-breath analysis of cardiorespiratory interaction for quantifying developmental maturity in premature infants. J Appl Physiol. 2012;112(5):859-67.

80. Takahashi AC, Porta A, Melo RC, Quiterio RJ, da Silva E, Borghi-Silva A, Tobaldini E, Montano N, Catai AM. Aging reduces complexity of heart rate variability assessed by conditional entropy and symbolic analysis. Intern Emerg Med. 2012;7(3):229-35.

81. Torres ME, Colominas MA, Schlotthauer G, Flandrin P. A Complete Ensemble Empirical Mode Decomposition with Adaptive Noise. 36th Int Conf on Acoustics, Speech and Signal Processing ICASSP; Prague, Czech Republic 2011.

82. Li H, Kwong S, Yang L, Huang D, Xiao D. Hilbert-huang transform for analysis of heart rate variability in cardiac health. IEEE/ACM Transactions on Computational Biology and Bioinformatics. 2011;8(6):1557-67.

83. Schiecke K, Wacker M, Piper D, Benninger F, Feucht M, Witte H. Time-variant, frequency-selective, linear and nonlinear analysis of heart rate variability in children with temporal lobe epilepsy. IEEE transactions on bio-medical engineering. 2014;61(6):1798808.

84. Marple LS. Computing the discrete-time " analytic" signal via fft. IEEE Trans Signal Process. 1999;47(9):2600-3.

85. Estevez M. Matlab Code of the Hilbert Marginal Spectrum (HMS) https://www.researchgate.net/publication/320161261; 2017 Accessed 10/01/2017.

86. Piskorski J, Guzik P, Krauze T, Zurek S. Cardiopulmonary resonance at $0.1 \mathrm{~Hz}$ demonstrated by averaged Lomb-Scargle periodogram. Cent Eur J Phys. 2010;8(3):386-92.

87. Montes-Brown J, Estévez-Báez M, Velázquez L. Disfunción autonómica cardiovascular en la Ataxia Espinocerebelosa. Madrid, España: Publicia; 2015.

88. Sivakumar SS, Namath AG, Tuxhorn IE, Lewis SJ, Galan RF. Decreased heart rate and enhanced sinus arrhythmia during interictal sleep demonstrate autonomic imbalance in generalized epilepsy. Journal of neurophysiology. 2016; DOI: 10.1152/jn.01120.2015.

89. Percival D, Walden T. Spectral Analysis for Physical Applications. Cambridge, UK: Cambridge University Press; 1993. 
90. Wichert S, Fokianos K, Strimmer K. Identifying Periodically Expressed Transcripts in Microarray Time Series Data. Bioinformatics. 2004;20:5-20.

91. Yeh JR, Sun WZ, Shieh JS, Huang NE. Intrinsic mode analysis of human heartbeat time series. Annals of biomedical engineering. 2010;38(4):1337-44.

92. Veerabhadrappa ST, Vyas AL, Anand S. Higher order spectral analysis of heart rate variability in pregnancy and postpartum. Conference proceedings : Annual International Conference of the IEEE Engineering in Medicine and Biology Society IEEE Engineering in Medicine and Biology Society Annual Conference. 2013;2013:2575-8.

93. Chang CC, Kao SC, Hsiao TC, Hsu HY. Assessment of autonomic nervous system by using empirical mode decomposition-based reflection wave analysis during nonstationary conditions. Physiological measurement. 2014;35(9):1873-83.

94. Sacha J. Why should one normalize heart rate variability with respect to average heart rate. Frontiers in physiology. 2013;4:306.

95. Sacha J. Interaction between Heart Rate and Heart Rate Variability. Annals of noninvasive electrocardiology : the official journal of the International Society for Holter and Noninvasive Electrocardiology, Inc. 2014;19(3):207-16.

96. Sacha J, Barabach S, Statkiewicz-Barabach G, Sacha K, Muller A, Piskorski J, Barthel P, Schmidt G. How to strengthen or weaken the HRV dependence on heart rate-description of the method and its perspectives. International journal of cardiology. 2013;168(2):1660-3.

97. Estévez-Báez M, Machado C, Leisman G, Brown-Martínez M, Jas-García JD, Montes-Brown J, Machado-García A, Carricarte-Naranjo C. A procedure to correct the effect of heart rate on heart rate variability indices: description and assessment. Int J Disabil Hum Dev DOI: 101515/ijdhd-2015-0014. 2015.

98. van Roon AM, Snieder H, Lefrandt JD, de Geus EJ, Riese H. Parsimonious Correction of Heart Rate Variability for Its Dependency on Heart Rate. Hypertension DOI: 101161/HYPERTENSIONAHA11608053. 2016.

99. Xia L. A very high frequency index of heart rate variability for evaluation of left ventricular systolic function and prognosis in chronic heart failure patients using five-minute electrocardiogram. J Geriatr Cardiol 2009;6(4):213-7.

100. Ozyilmaz I, Ergul Y, Tola HT, Saygi M, Ozturk E, Tanidir IC, Tosun O, Ozyilmaz S, Gul M, Guzeltas A, et al. Heart rate variability improvement in children using transcatheter atrial septal defect closure. Anatolian journal of cardiology. 2015; DOI: 10.5152/akd.2015.5922.

101. Estevez M, Machado C, Montes-Brown J, Jas-García JD, Leisman G, Schiavi A, Machado-García A, Carricarte-Naranjo C, Carmeli E. Very High Frequency Oscillations of Heart Rate Variability in Healthy Humans and in Patients with Cardiovascular Autonomic Neuropathy. Adv Exp Med Biol 2017; DOI 10.1007/5584_2018_154.

102. Norris PR, Morris JA, Jr., Ozdas A, Grogan EL, Williams AE. Heart rate variability predicts trauma patient outcome as early as $12 \mathrm{~h}$ : implications for military and civilian triage. J Surg Res. 2005;129(1):122-8. 
103. Goldstein B, Toweill D, Lai S, Sonnenthal K, Kimberly B. Uncoupling of the autonomic and cardiovascular systems in acute brain injury. Am J Physiol. 1998;275(4 Pt 2):R1287-92.

104. King DR, Ogilvie MP, Pereira BM, Chang Y, Manning RJ, Conner JA, Schulman CI, McKenney MG, Proctor KG. Heart rate variability as a triage tool in patients with trauma during prehospital helicopter transport. J Trauma. 2009;67(3):436-40.

105. Garcia-Gonzalez MA, Fernandez-Chimeno M, Ramos-Castro J. Bias and uncertainty in heart rate variability spectral indices due to the finite ECG sampling frequency. Physiological measurement. 2004;25(2):489-504.

106. Merri M, Farden DC, Mottley JG, Titlebaum EL. Sampling frequency of the electrocardiogram for spectral analysis of the heart rate variability. IEEE transactions on biomedical engineering. 1990;37(1):99-106.

107. Ellis RJ, Zhu B, Koenig J, Thayer JF, Wang Y. A careful look at ECG sampling frequency and R-peak interpolation on short-term measures of heart rate variability. Physiological measurement. 2015;36(9):1827-52.

108. Daskalov IK, Christov I. Improvement of resolution in measurement of electrocardiogram RR intervals by interpolation Med Eng Phys. 1997;1(9):375-9.

109. Laguna P, Moody GB, Mark RG. Power spectral density of unevenly sampled data by least-square analysis: performance and application to heart rate signals. IEEE Trans Biomed Eng 1998 Jun;45(6):698-715. 1998.

110. Estévez M, Machado C, Leisman G, Estévez-Hernández T, Arias-Morales A, Machado A, Montes-Brown J. Spectral analysis of heart rate variability. Int J Disabil Hum Dev. 2015; DOI: 10.1515/ijdhd-2014-0025.

111. Yen JL. On nonuniform sampling of bandwidth-limted signals. Trans Circuit Theory. 1956;CT-3:251-7.

112. Clifford GD, Tarassenko L. Quantifying errors in spectral estimates of HRV due to beat replacement and resampling. IEEE transactions on bio-medical engineering. 2005;52(4):630-8.

113. Cersosimo M, Benarroch E. Central control of autonomic function and involvement in neurodegenerative disorders. In: Buijs R, Swaab D, editors. Handbook of Clinical Neurology, The Autonomic Nervous System. 117. Edinburgh London New York Oxford Philadelphia St Louis Sydney Toronto: Elsevier B.V.; 2014.

114. Baguley IJ, Heriseanu RE, Felmingham KL, Cameron ID. Dysautonomia and heart rate variability following severe traumatic brain injury. Brain Inj. 2006;20(4):437-44.

115. Baguley IJ, Heriseanu RE, Nott MT, Chapman J, Sandanam J. Dysautonomia after severe traumatic brain injury: evidence of persisting overresponsiveness to afferent stimuli. Am J Phys Med Rehabil. 2009;88(8):615-22.

116. Fernandez-Ortega JF, Prieto-Palomino MA, Garcia-Caballero M, Galeas-Lopez JL, Quesada-Garcia G, Baguley IJ. Paroxysmal sympathetic hyperactivity after traumatic brain injury: clinical and prognostic implications. Journal of neurotrauma. 2012;29(7):1364-70. 
117. Marthol H, Intravooth T, Bardutzky J, De Fina P, Schwab S, Hilz MJ. Sympathetic cardiovascular hyperactivity precedes brain death. Clin Auton Res. 2010;20:363-9.

118. Fugate J, Rabinstein A, Wijdicks F. Blood Pressure Patterns After Brain Death. Neurology. 2011;77:399.

119. Korpelainen JT, Huikuri HV, Sotaniemi KA, Myllyla VV. Abnormal heart rate variability reflecting autonomic dysfunction in brainstem infarction. Acta neurologica Scandinavica. 1996;94(5):337-42.

120. Bernardi L, Keller F, Sanders M, Reddy PS, Griffith B, Meno F, Pinsky MR. Respiratory sinus arrhythmia in the denervated human heart. J Appl Physiol. 1989;67:144755 .

121. Bernardi L, Salvucci F, Suardi R, Solda PL, Calciati A, Perlini S, Falcone C, Ricciardi L. Evidence for an intrinsic mechanism regulating heart rate variability in the transplanted and the intact heart during submaximal dynamic exercise? Cardiovascular research. 1990;24(12):969-81.

122. Mateo J, Serrano P, Bailón R, Olmos S, García J, del Río A, Ferreira I, Laguna P. ECG-based clinical indexes during exercise test including repolarization, depolarization and HRV. Computers in cardiology (IEEE Computer Society Press). 2001;28:309-12.

123. Mateo J, Serrano P, Bailón R, Olmos S, García J, Del Río A, Ferreira I, Laguna P. Heart rate variability measurements during exercise test may improve the diagnosis of ischemic heart disease. 23rd Annual International Conference of the IEEE Engineering in Medicine and Biology Society; October 25-28 2001; Istanbul, Turkey. Turkey 2001.

124. Bailon R, Mateo J, Olmos S, Serrano P, Garcia J, del Rio A, Ferreira IJ, Laguna P. Coronary artery disease diagnosis based on exercise electrocardiogram indexes from repolarisation, depolarisation and heart rate variability. Medical \& biological engineering \& computing. 2003;41(5):561-71.

125. Toledo E, Pinhas I, Aravot D, Akselrod S. Very high frequency oscillations in the heart rate and blood pressure of heart transplant patients. Medical \& biological engineering \& computing. 2003;41(4):432-8.

126. Toledo E, Pinhas I, Aravot D, Almog Y, Akselrod S. Functional restitution of cardiac control in heart transplant patients. Am J Physiol Regulatory Integrative Comp Physiol. 2002;282:R900-R8.

127. Pinhas I, Toledo E, Aravot D, Akselrod S. Bicoherence analysis of new cardiovascular spectral components observed in heart-transplant patients: statistical approach for bicoherence thresholding. IEEE transactions on bio-medical engineering. 2004;51(10):1774-83.

128. Riganello F. Responsiveness and the autonomic control two-way interaction in disorders of consciousness. In: Moni MM, Samnita WG, editors. Brain function and responsiveness in disorders of consciousness. Switzerland: Springer International Publishing; 2016. 


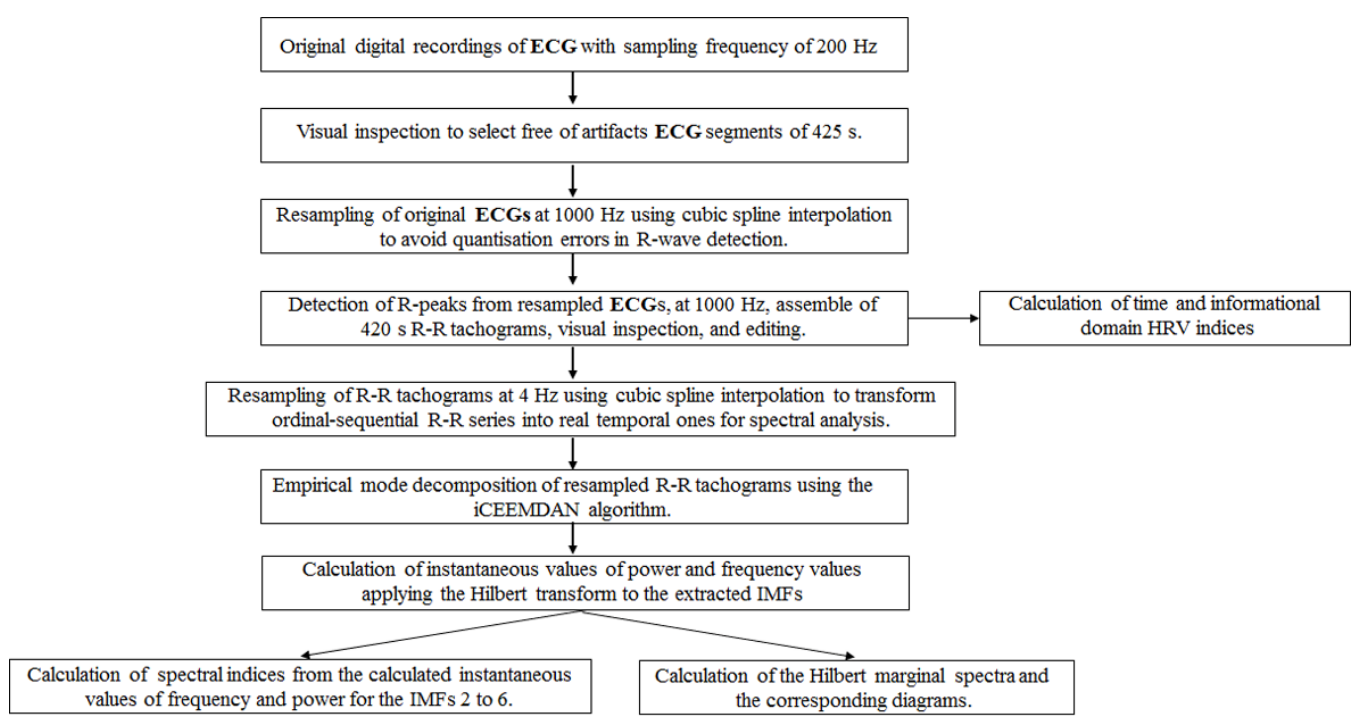

Figure 1. Schematic diagram of the main steps included in the processing of the ECG in this study.

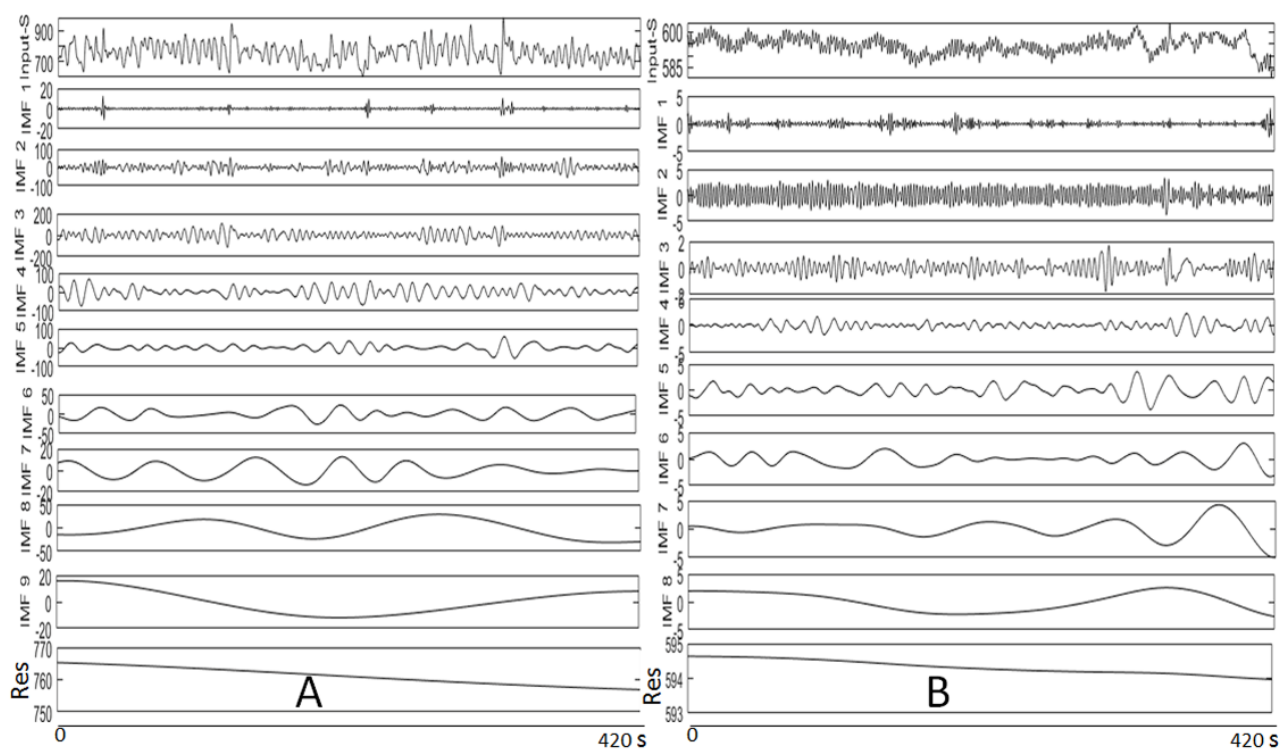

Figure 2. Results of the decomposition process using the improved complete ensemble empirical mode decomposition (iCEEMDAN) method in a control subject (A) and in a patient in coma with GCS 3 (B). In both subjects the top plots correspond to the resampled by interpolation R-R tachograms submitted to the process. The total duration of the investigated tachograms was 420 seconds. The Y-axes scale correspond to milliseconds. Plots labeled as IMFs correspond to the successively extracted intrinsic modal functions (IMFs). The bottom plots labeled as "Res" include the residue of the so called sifting process, after extraction of all the IMFs. 


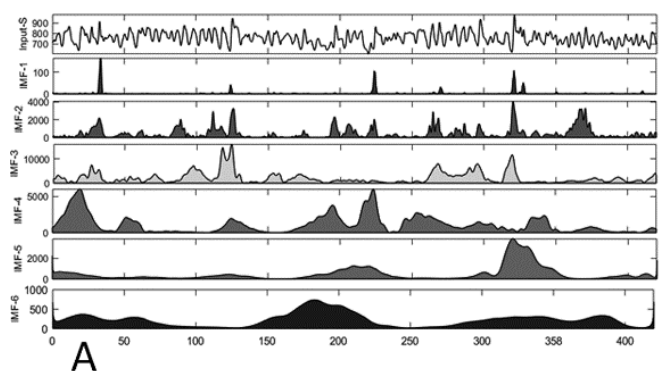

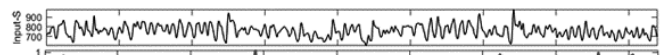

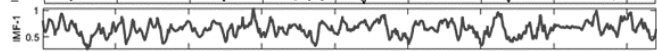

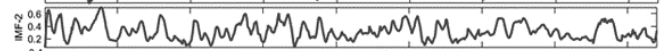

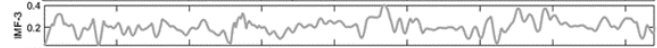

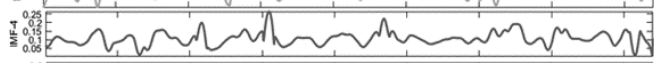

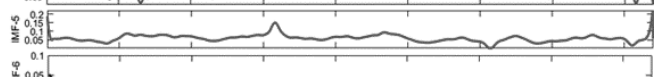

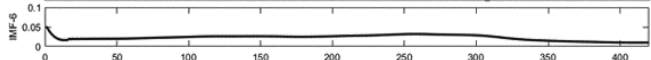

B
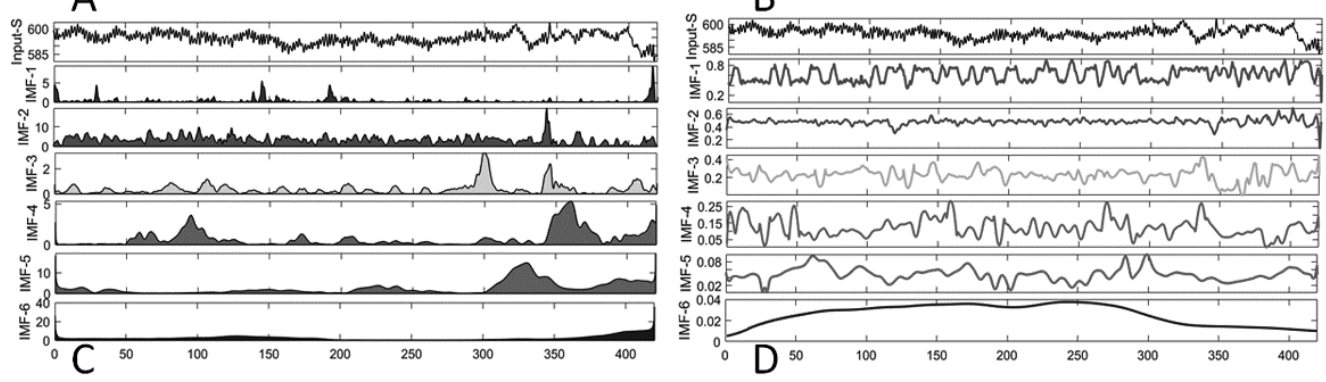

Figure 3. Diagrams showing the instantaneous spectral power (A and C) and frequency (B and D) values of the first 6 extracted modal components (IMFs) obtained from the analysis of the R-R tachograms from free of artefacts electrocardiographic recordings (420 s) using the Hilbert-Huang transform in a control subject (A and B), and in a patient in coma with a GCS 3 (C and D). The top plot of all diagrams shows the interpolated R-R tachogram. The $\mathrm{Y}$ axes of the plots of the instantaneous power values in diagrams $\mathrm{A}$ and $\mathrm{C}$ represent values expressed in units of squared milliseconds, while the $\mathrm{Y}$ axes of the corresponding plots of the instantaneous frequencies in diagrams B and D represent values expressed in units of $\mathrm{Hz}$.
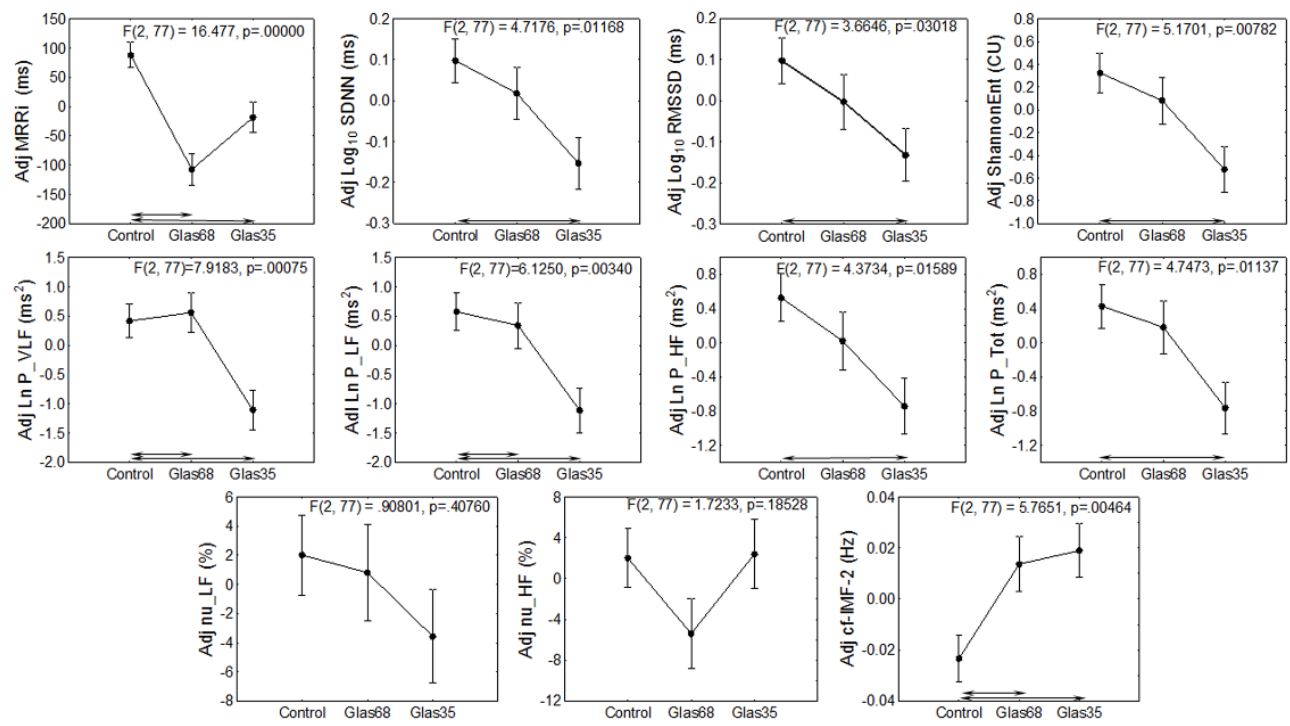

Figure 4. Comparison of HRV measurements that required adjustment (Adj). Vertical bars denote +/- standard errors. The results of the F statistic and the associated probability (p) of the one-way ANOVA tests are shown in the upper part of each diagram. Significant results of the post hoc Scheffe's tests are represented with double-arrow lines for $\mathrm{p}<0.01$. 


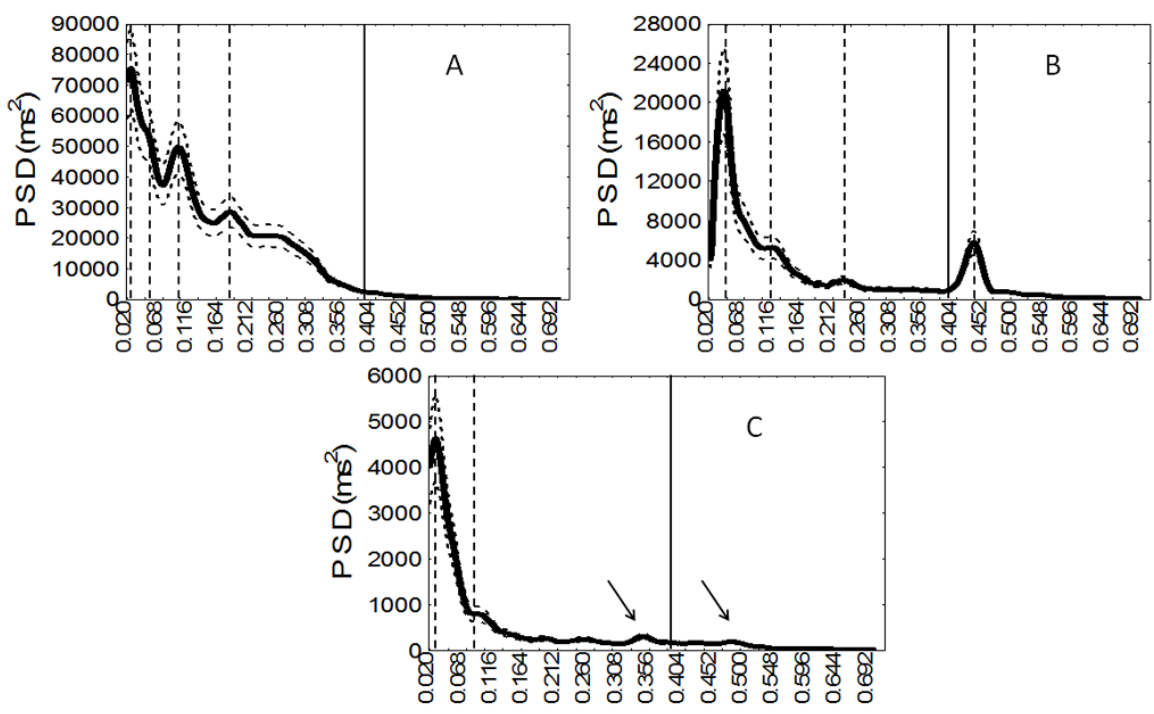

Figure 5. Grand averages of the Hilbert marginal spectra (HMS) corresponding to the control subjects (A), the patients in coma with GCS from 6 to 8 (B), and the patients in coma with GCS from 3 to 5 (C), in the spectral range from 0.02 to $0.7 \mathrm{~Hz}$ represented with thick heavy continuous lines. Upper and lower discontinuous lines represent the interval of one standard error around the mean grand averages. Vertical dashed lines depict visually identified peaks. Vertical continuous lines depict the frequency limit for 0.4 $\mathrm{Hz}$. Arrows in $\mathrm{C}$ point to possible very low amplitude peaks in the HF and VHF spectral ranges of heart rate variability of these comatose patients. 

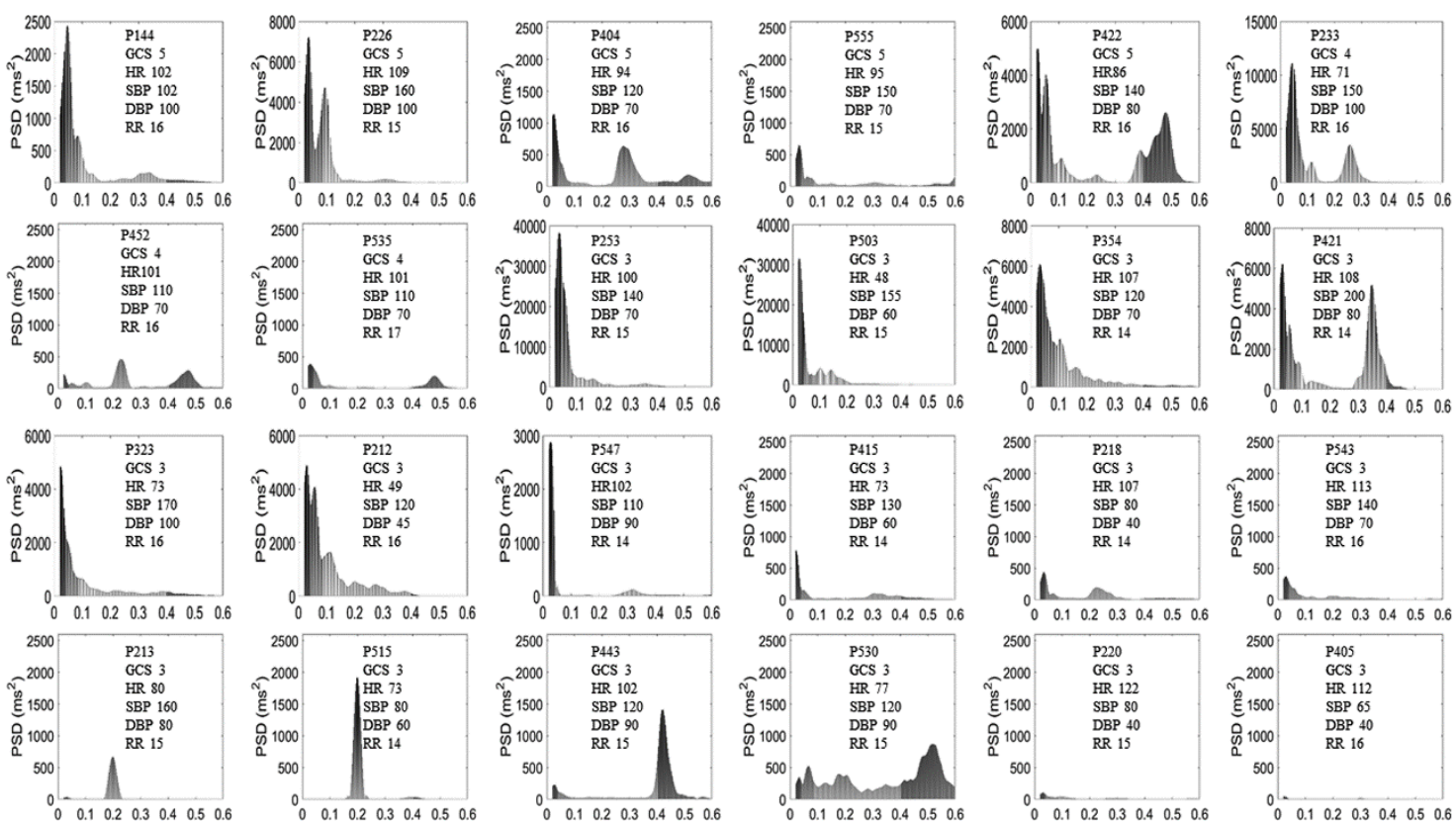

Figure 6. Individual power Hilbert marginal spectra (HMS) of all the studied patients with Glasgow coma scores from 3 to 5 . Values in the $\mathrm{X}$ axis represent spectral frequencies in $\mathrm{Hz}$. In the $\mathrm{Y}$ axis are represented the values for the power spectral density (PSD) expressed in $\mathrm{ms}^{2}$. The maximal value in the $\mathrm{Y}$ axis was fixed to $2600 \mathrm{~ms}^{2}$ for those spectra that showed a maximal value of the PSD under that value, estimated from statistical criteria detailed in the results section. The information included inside each spectral diagram indicates the individual corresponding values for the patient's conventional identification label (P\#\#\#), the Glasgow coma score (GCS), heart rate (HR), systolic blood pressure (SBP), diastolic blood pressure (DBP), and respiratory rate (RR). The HMS of patients labelled as P213, P443, P503, P515, P530, and P547 were classified as pattern A: PSD present but limited to a peak of the VLF, the HF or the VHF band; the spectra of patients P255, P452, P535, P218, P220, P405, P415, and P543 were classified as presenting a pattern B: markedly reduced values of PSD $\left(<1000 \mathrm{~ms}^{2}\right)$ without evidence of relevant peaks assessed by the Fisher's g-Statistic; the spectra of patients P144, P404, P422, P212 and P323 were classified as pattern C: reduced values of PSD values $\left(1000-6000 \mathrm{~ms}^{2}\right)$ with identifiable peaks in the VLF and LF bands; the spectra of patients P226, P354, and P421 were classified as pattern D: PSD values higher than $6000 \mathrm{~ms}^{2}$ with identifiable peaks; the spectra of patients P233, and P253 were classified as pattern E: PSD over 12,000 $\mathrm{ms}^{2}$ with well-defined peaks. 

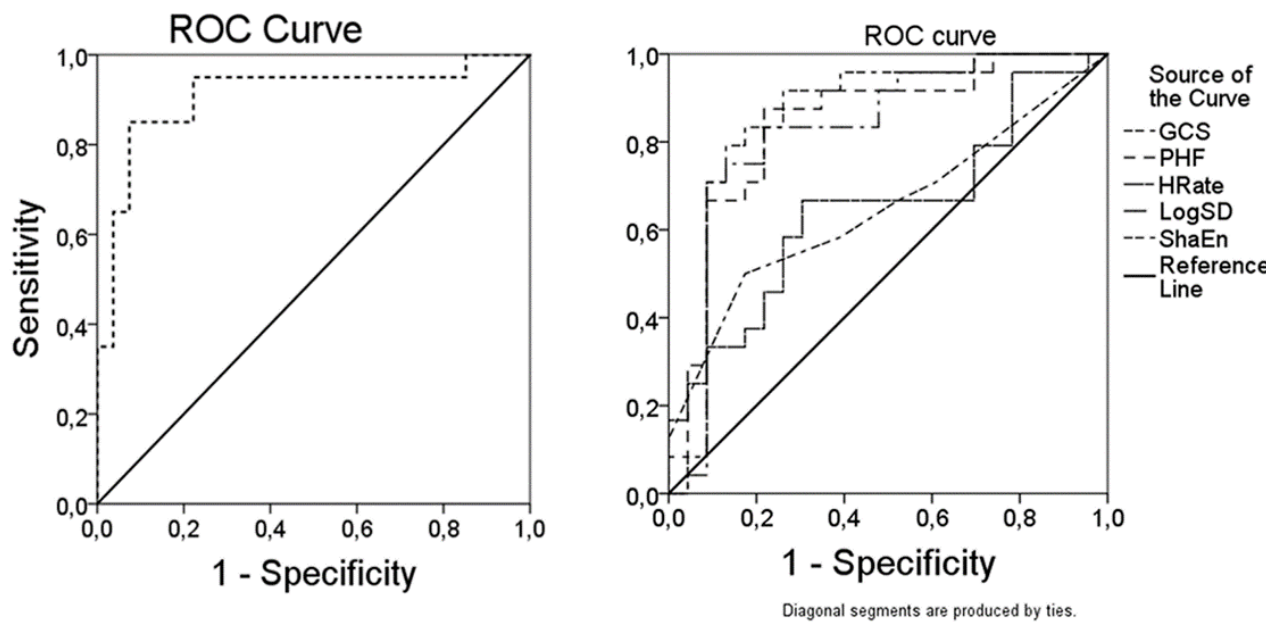

Figure 7. ROC curves for the prediction of mortality estimated using forward Wald stepwise multiple logistic regression. The left diagram shows the curve corresponding to the obtained model expressed with the equation "Mortality Score $=9.378+0.558^{*}(\mathrm{nu}-\mathrm{VHF})-2.164 *(\mathrm{P}-\mathrm{LF})+1.585^{*}(\mathrm{P}-\mathrm{VLF})$ ", with an area under the curve (AUC) of 0.939 , indicating a good efficiency (accuracy). The diagram on the right shows the ROC curves estimated using the univariate logistic regression for other variables not included by this model. The values of the AUC for those variables were: GCS (0.648), HRate (0.649), Log SD (0.824), PHF (0.842), and ShaEn (0.857). 
Table 1. Demographic and physiological variables of the patients in coma and the control healthy subjects.

\begin{tabular}{lcccc}
\hline \multicolumn{1}{c}{ Indices } & $\begin{array}{c}\text { Controls } \\
(\mathrm{N}=33)\end{array}$ & $\begin{array}{c}\text { Glas68 } \\
(\mathrm{N}=23)\end{array}$ & $\begin{array}{c}\text { Glas35 } \\
(\mathrm{N}=24)\end{array}$ & $\begin{array}{c}\text { Statistical } \\
\text { significance }\end{array}$ \\
\hline Gender (Males/Females) & $16 / 17$ & $11 / 12$ & $11 / 13$ & $\chi^{2}=0.04 \mathrm{p}=0.98$ \\
Age (years) & $46.4 \pm 18$ & $52.3 \pm 19$ & $56.6 \pm 14$ & $\mathrm{~F}=2.48 \mathrm{p}=0.09$ \\
Systolic blood pressure (mmHg) & $115.0 \pm 13$ & $117.8 \pm 24$ & $126.2 \pm 31$ & $\mathrm{~F}=1.71 \mathrm{p}=0.19$ \\
Diastolic blood pressure (mmHg) & $73.8 \pm 9$ & $71.5 \pm 18$ & $76.0 \pm 21$ & $\mathrm{~F}=0.46 \mathrm{p}=0.63$ \\
Respiratory frequency (cycles/min) & $14.45 \pm 1.8$ & $15.82 \pm 0.98^{*}$ & $15.21 \pm 0.88^{*}$ & $\mathrm{~F}=6.91 \mathrm{p}=0.002$ \\
Mean heart period duration (ms) & $920.3 \pm 120$ & $659.3 \pm 115^{* *}$ & $685.0 \pm 171^{*}$ & $\mathrm{~F}=32.38 \mathrm{p}=0.000 \ldots$ \\
\hline
\end{tabular}

Note. Results are presented as mean values \pm standard deviations. Values of statistical significance for the chi-squared $\left(\chi^{2}\right)$ and one-way ANOVA tests are shown including the Fisher's $\mathrm{F}$ statistic and their associated probabilities (p). Glas68, patients with Glasgow coma score (GCS) from 6 to 8; Glas35, patients with GCS from 3 to 5; RRi, R-R heart inter-beat intervals; ${ }^{*} \mathrm{p}<0.05,{ }^{* *} \mathrm{p}<0.01$ for Scheffe's post hoc tests (comparisons against the control group).

Table 2. Aetiology of the main brain lesions of the patients in coma. Results are presented in number and percentage.

\begin{tabular}{lcc}
\hline \multicolumn{1}{c}{ Aetiology of brain lesions } & $\begin{array}{c}\text { Glas68 } \\
\text { Group }\end{array}$ & $\begin{array}{c}\text { Glas35 } \\
\text { Group }\end{array}$ \\
\hline Subarachnoid haemorrhage & $6(26.7 \%)$ & $5(20.3 \%)$ \\
Ischaemic cerebral infarct & $6(25.8 \%)$ & $7(29.3 \%)$ \\
Intracranial hypertension & $2(8.6 \%)$ & $3(12.6 \%)$ \\
Hypertensive encephalopathy & $2(8.6 \%)$ & $2(8.4 \%)$ \\
Hypoxic encephalopathy & $5(21.7 \%)$ & $1(4.2 \%)$ \\
Septic shock & $1(4.3 \%)$ & $3(12.6 \%)$ \\
Acute renal failure & - & $2(8.4 \%)$ \\
Metabolic encephalopathy & $1(4.3 \%)$ & $1(4.2 \%)$ \\
Totals & 23 & 24 \\
\hline
\end{tabular}


Table 3. Correlation values calculated between some demographic and physiological variables and the studied HRV indices for the whole group of patients in coma and control healthy subjects.

\begin{tabular}{lcccccc}
\hline HRV indices & Gender & Age & SBP & DBP & RRate & MRRi \\
\hline Ln P-VLF & 0.06 & $\mathbf{- 0 . 2 1}$ & $\mathbf{0 . 2 2}$ & $\mathbf{0 . 2 5}$ & $\mathbf{- 0 . 3 7}$ & $\mathbf{0 . 5 5}$ \\
Ln P-LF & 0.02 & $\mathbf{- 0 . 2 3}$ & -0.05 & 0.08 & $\mathbf{- 0 . 4 5}$ & $\mathbf{2 . 5 9}$ \\
Ln P-HF & -0.06 & $\mathbf{- 0 . 3 0}$ & -0.08 & 0.02 & $\mathbf{- 0 . 4 8}$ & $\mathbf{0 . 6 8}$ \\
Ln P-VHF & -0.02 & -0.16 & -0.10 & 0.02 & $\mathbf{- 0 . 2 8}$ & $\mathbf{0 . 2 1}$ \\
Ln P-Tot & -0.01 & $\mathbf{- 0 . 2 8}$ & -0.06 & 0.07 & $\mathbf{- 0 . 4 8}$ & $\mathbf{0 . 6 3}$ \\
nu-VLF & $\mathbf{0 . 2 0}$ & 0.13 & $\mathbf{0 . 2 5}$ & $\mathbf{0 . 2 2}$ & $\mathbf{0 . 2 2}$ & $\mathbf{- 0 . 2 0}$ \\
nu-LF & $\mathbf{0 . 2 7}$ & 0.03 & -0.07 & 0.0 & $\mathbf{- 0 . 2 8}$ & $\mathbf{0 . 2 7}$ \\
nu-HF & -0.19 & $\mathbf{- 0 . 2 9}$ & -0.07 & -0.10 & $\mathbf{- 0 . 2 0}$ & $\mathbf{0 . 3 6}$ \\
nu-VHF & 0.01 & 0.17 & -0.03 & -0.09 & $\mathbf{0 . 3 1}$ & $\mathbf{- 0 . 4 6}$ \\
Log 10 LF/HF & $\mathbf{0 . 3 1}$ & 0.13 & 0.07 & 0.13 & 0.01 & -0.01 \\
Sha-Ent & -0.02 & $\mathbf{- 0 . 2 5}$ & -0.03 & 0.09 & $\mathbf{- 0 . 4 9}$ & $\mathbf{0 . 6 3}$ \\
Log 10 SDNN & -0.02 & $\mathbf{- 0 . 2 6}$ & -0.03 & 0.08 & $\mathbf{- 0 . 4 9}$ & $\mathbf{0 . 6 2}$ \\
Log 10 RMSSD & -0.03 & $\mathbf{- 0 . 2 5}$ & -0.12 & -0.02 & $\mathbf{- 0 . 5 0}$ & $\mathbf{0 . 6 8}$ \\
cf-imf-1 & 0.03 & -0.05 & -0.01 & 0.06 & $\mathbf{0 . 4 3}$ & $\mathbf{- 0 . 8 5}$ \\
cf-imf-2 & -0.02 & $\mathbf{0 . 2 0}$ & 0.06 & 0.02 & $\mathbf{0 . 3 0}$ & $\mathbf{- 0 . 7 9}$ \\
cf-imf-3 & -0.06 & 0.16 & 0.06 & 0.07 & $\mathbf{0 . 3 2}$ & $\mathbf{0 . 4 8}$ \\
cf-imf-4 & 0.09 & 0.15 & 0.14 & 0.03 & 0.19 & $\mathbf{- 0 . 2 5}$ \\
cf-imf-5 & 0.05 & -0.08 & 0.02 & -0.16 & 0.07 & -0.08 \\
cf-imf-6 & 0.10 & 0.12 & -0.03 & -0.14 & -0.02 & 0.03 \\
\hline
\end{tabular}

Note. Abbreviations for HRV indices are detailed in Methods; for the categorical variable Gender the correlation was calculated with the Spearman's rank index; for other variables was used the Pearson's moment product correlation index. Highlighted values resulted significant at least for $\mathrm{p}<0.05$; SBP, systolic blood pressure; DBP, diastolic blood pressure; RRate, respiratory frequency. 
Table 4. Comparative analysis between the groups of patients and the control group for the calculated HRV indices without adjustments.

\begin{tabular}{|c|c|c|c|c|c|c|}
\hline Indices & $\begin{array}{l}\text { Control } \\
(\mathrm{n}=33)\end{array}$ & $\begin{array}{c}\text { Glas68 } \\
(\mathrm{n}=23)\end{array}$ & $\begin{array}{c}\text { Glas35 } \\
(\mathrm{n}=24)\end{array}$ & $\mathrm{F}(2,77)$ & $\mathrm{p}$ & $\mathrm{Pw}$ \\
\hline MRRi (ms) & $920.3 \pm 120$ & $659.3 \pm 115 *$ & $685.0 \pm 171 *$ & 32.378 & $0.0 \ldots$ & 1.0 \\
\hline $\log _{10} \operatorname{SDNN}(\mathrm{ms})$ & $1.687 \pm 0.21$ & $1.119 \pm 0.43 *$ & $0.897 \pm 0.32 *$ & 46.654 & $0.0 \ldots$ & 1.0 \\
\hline $\log _{10} \operatorname{RMSSD}(\mathrm{ms})$ & $1.539 \pm 0.27$ & $0.883 \pm 0.46 *$ & $0.718 \pm 0.26 *$ & 49.158 & $0.0 \ldots$ & 1.0 \\
\hline nDRRs (n) & $176.12 \pm 49.9$ & $84.61 \pm 53.2 *$ & $49.58 \pm 32.5 * \S$ & 57.037 & $0.0 \ldots$ & 1.0 \\
\hline $\mathrm{W}(\mathrm{ms})$ & $307.84 \pm 110.2$ & $120.87 \pm 97.8 *$ & $58.58 \pm 43.9 * \S$ & 58.213 & $0.0 \ldots$ & 1.0 \\
\hline NRatio (NU) & $0.3766 \pm 0.110$ & $0.1381 \pm 0.098 *$ & $0.0833 \pm 0.060 *$ & 79.414 & $0.0 \ldots$ & 1.0 \\
\hline Sha-Ent (CU) & $7.393 \pm 0.64$ & $5.524 \pm 1.41 *$ & $4.757 \pm 1.07 * \S$ & 48.977 & $0.0 \ldots$ & 1.0 \\
\hline $\operatorname{Ln}$ P-VLF $\left(\mathrm{ms}^{2}\right)$ & $13.036 \pm 1.02$ & $10.887 \pm 2.05 * *$ & $9.087 \pm 2.23 * *$ & 7.213 & 0.001 & 0.92 \\
\hline $\operatorname{Ln} \mathrm{P}-\mathrm{LF}\left(\mathrm{ms}^{2}\right)$ & $14.038 \pm 1.18$ & $11.066 \pm 2.31 * *$ & $9.242 \pm 2.42 * * \S$ & 43.411 & $0.0 \ldots$ & 1.0 \\
\hline Ln P-HF $\left(\mathrm{ms}^{2}\right)$ & $13.859 \pm 1.40$ & $10.288 \pm 2.25 * *$ & $9.371 \pm 1.52 * *$ & 54.614 & 0.0. & 1.0 \\
\hline $\operatorname{Ln}$ P-VHF $\left(\mathrm{ms}^{2}\right)$ & $10.239 \pm 1.38$ & $9.708 \pm 1.94 * *$ & $8.639 \pm 1.43 * *$ & 7.213 & 0.001 & 0.92 \\
\hline Ln P-Tot $\left(\mathrm{ms}^{2}\right)$ & $14.943 \pm 1.13$ & $12.186 \pm 2.13 * *$ & $11.001 \pm 1.52 * * \S$ & 49.301 & $0.0 \ldots$ & 1.0 \\
\hline nu-VLF (\%) & $18.1 \pm 12$ & $32.6 \pm 12 * *$ & $22.7 \pm 14 * \S$ & 6.249 & 0.003 & 0.88 \\
\hline nu-LF $(\%)$ & $42.9 \pm 14$ & $36.2 \pm 16 *$ & $27.7 \pm 20 * *$ & 5.588 & 0.0005 & 0.84 \\
\hline nu-HF $(\%)$ & $37.5 \pm 18$ & $16.8 \pm 7 * *$ & $26.7 \pm 16 *$ & 8.947 & 0.0003 & 0.97 \\
\hline nu-VHF (\%) & $1.5 \pm 2$ & $14.5 \pm 9 * *$ & $22.8 \pm 12 * * \S$ & 13.341 & 0.0001 & 0.99 \\
\hline $\mathrm{Ln} \mathrm{LF/HF} \mathrm{ratio}$ & $0.198 \pm 0.81$ & $0.778 \pm 0.63$ & $-0.128 \pm 1.82$ & 2.072 & 0.13 & 0.41 \\
\hline cf-IMF-2 (Hz) & $0.334 \pm 0.06$ & $0.473 \pm 0.04 * *$ & $0.468 \pm 0.07 * *$ & 50.244 & $0.0 \ldots$ & 1.0 \\
\hline cf-IMF-3 (Hz) & $0.239 \pm 0.03$ & $0.268 \pm 0.04 * *$ & $0.266 \pm 0.04 * *$ & 5.554 & 0.005 & 0.84 \\
\hline cf-IMF-4 (Hz) & $0.113 \pm 0.01$ & $0.122 \pm 0.02 * *$ & $0.129 \pm 0.02 * *$ & 8.531 & 0.004 & 0.96 \\
\hline cf-IMF-5 (Hz) & $0.057 \pm 0.01$ & $0.060 \pm 0.01$ & $0.060 \pm 0.01$ & 1.504 & 0.23 & 0.31 \\
\hline cf-IMF-6 (Hz) & $0.029 \pm 0.001$ & $0.028 \pm 0.0004$ & $0.030 \pm 0.006$ & 0.675 & 0.51 & 0.16 \\
\hline
\end{tabular}

Note. Abbreviations for HRV indices are detailed in Methods; CU, conventional units; NU, non-dimensional units; F, Fisher's F statistic for the one-way ANOVA tests; $\mathrm{p}$, associated probability to the $\mathrm{F}$ values; $\mathrm{Pw}$, power values associated with the significance of the F-tests for $\alpha=0.05 ; 0.0 \ldots$, probability associated to the $\mathrm{F}$ Statistic values for at least $\mathrm{p}<0.00001 ; *, \mathrm{p}<0.01$ for Scheffe's post hoc tests (comparisons with the control group); $\S, \mathrm{p}<0.05$ for Scheffe's post hoc tests (comparisons between the patients' groups). 
Table 5. Summary of the calculations related with the adjustment procedure used in this study to cope with the effect of different confounding factors.

\begin{tabular}{|c|c|c|c|c|c|c|c|c|}
\hline \multirow[t]{2}{*}{ HRV index } & & \multicolumn{4}{|c|}{$\begin{array}{l}\text { Estimated coefficients of the linear } \\
\text { regression model }\end{array}$} & \multirow[t]{2}{*}{$\mathrm{F}(6,73)$} & \multirow[t]{2}{*}{$\mathrm{P}$} & \multirow[t]{2}{*}{$\mathrm{K}-\mathrm{S}$} \\
\hline & & $\begin{array}{c}\beta \\
\text { Estimates }\end{array}$ & SEM & t-Stat & $\mathrm{p}$ & & & \\
\hline \multirow{7}{*}{$\begin{array}{l}\text { Ln P-VLF } \\
\quad\left(\mathrm{ms}^{2}\right)\end{array}$} & Intercept & 6.589156 & 2.119089 & 3.11 & 0.003 & \multirow{7}{*}{10.481} & \multirow{7}{*}{$0.0 \ldots$} & \multirow{7}{*}{$\begin{array}{l}0.081 \\
p>0.2\end{array}$} \\
\hline & Gender & 0.750561 & 0.458708 & 1.64 & 0.106 & & & \\
\hline & Age & -0.025827 & 0.012372 & -2.09 & 0.040 & & & \\
\hline & SBP & -0.022988 & 0.015812 & -1.45 & 0.150 & & & \\
\hline & DBP & 0.068290 & 0.022681 & 3.01 & 0.0036 & & & \\
\hline & RRate & -0.099558 & 0.057425 & -1.73 & 0.087 & & & \\
\hline & MRRi & 0.006419 & 0.001386 & 4.63 & 0.000015 & & & \\
\hline \multirow{7}{*}{$\begin{array}{l}\mathrm{Ln} \text { P-VHF } \\
\quad\left(\mathrm{ms}^{2}\right)\end{array}$} & Intercept & 11.17621 & 1.881194 & 5.94 & $0.0 \ldots$ & \multirow{7}{*}{2.016} & \multirow{7}{*}{0.07} & \multirow{7}{*}{$\begin{array}{l}0.063 \\
p>0.2\end{array}$} \\
\hline & Gender & 0.28657 & 0.407212 & 0.70 & 0.48 & & & \\
\hline & Age & -0.01474 & 0.010983 & -1.34 & 0.18 & & & \\
\hline & SBP & -0.01805 & 0.014037 & -1.29 & 0.20 & & & \\
\hline & DBP & 0.02921 & 0.020134 & 1.45 & 0.15 & & & \\
\hline & RRate & -0.09034 & 0.050979 & -1.77 & 0.08 & & & \\
\hline & MRRi & 0.00075 & 0.001230 & 0.61 & 0.54 & & & \\
\hline \multirow{7}{*}{$\begin{array}{l}\text { nu-VLF } \\
(\%)\end{array}$} & Intercept & 3.307403 & 18.17917 & 0.18 & 0.86 & \multirow{7}{*}{1.551} & \multirow{7}{*}{0.174} & \multirow{7}{*}{$\begin{array}{l}0.071 \\
p>0.2\end{array}$} \\
\hline & Gender & 1.878704 & 3.93515 & 0.48 & 0.63 & & & \\
\hline & Age & 0.116226 & 0.10614 & 1.10 & 0.28 & & & \\
\hline & SBP & -0.008193 & 0.13565 & -0.06 & 0.95 & & & \\
\hline & DBP & 0.199319 & 0.19457 & 1.02 & 0.31 & & & \\
\hline & RRate & 0.402386 & 0.49264 & 0.82 & 0.42 & & & \\
\hline & MRRi & -0.009456 & 0.01189 & -0.79 & 0.43 & & & \\
\hline \multirow{7}{*}{$\begin{array}{c}\text { nu-LF } \\
(\%)\end{array}$} & Intercept & 42.37303 & 18.88041 & 2.24 & 0.03 & \multirow{7}{*}{3.514} & \multirow{7}{*}{0.004} & \multirow{7}{*}{$\begin{array}{l}0.057 \\
p>0.2\end{array}$} \\
\hline & Gender & 12.99162 & 4.08694 & 3.16 & 0.002 & & & \\
\hline & Age & -0.03017 & 0.11023 & -0.27 & 0.78 & & & \\
\hline & SBP & -0.05770 & 0.14088 & -0.41 & 0.68 & & & \\
\hline & DBP & 0.15532 & 0.20208 & 0.77 & 0.44 & & & \\
\hline & RRate & -1.31285 & 0.51164 & -2.56 & 0.012 & & & \\
\hline & MRRi & 0.00844 & 0.01235 & 0.68 & 0.50 & & & \\
\hline \multirow{7}{*}{$\begin{array}{l}\text { nu-VHF } \\
(\%)\end{array}$} & Intercept & 43.81720 & 18.01290 & 2.43 & 0.017 & \multirow{7}{*}{1.662} & \multirow{7}{*}{0.158} & \multirow{7}{*}{$\begin{array}{l}0.062 \\
p>0.20\end{array}$} \\
\hline & Gender & -2.60361 & 3.89915 & -0.67 & 0.51 & & & \\
\hline & Age & 0.15292 & 0.10517 & 1.45 & 0.15 & & & \\
\hline & SBP & 0.04507 & 0.13441 & 0.33 & 0.74 & & & \\
\hline & DBP & -0.25229 & 0.19279 & -1.31 & 0.19 & & & \\
\hline & RRate & 0.48979 & 0.48813 & 1.00 & 0.32 & & & \\
\hline & MRRi & -0.04361 & 0.01178 & -3.70 & 0.0004 & & & \\
\hline
\end{tabular}

Note. For reasons of space in the table are only included some HRV spectral indices. The complete analysis is included in supplementary information and can be downloaded from https://www.researchgate.net/publication/325130068; Abbreviations of HRV indices are detailed in Methods; F(m,n), F-Statistic for $\mathrm{m}, \mathrm{n}$ respective degrees of freedom; $\mathrm{P}$, associated probability to the corresponding F-Statistic values; K, Value of the Kolmogorov-Smirnov's tests and associated probability for rejecting the hypothesis of normality of the calculated residuals; t-Stat, t-Statistic; SEM, standard error of the means; $0.0 \ldots$ highly significant values for at least $\mathrm{p}<0.00001$. 
Table 6. Analysis of the group of patients in coma with Glasgow coma score $=3$, considering different demographic, vital, and clinical indices, etiological factors, HRV spectral patterns, and the global clinical assessment of the autonomic nervous system.

\begin{tabular}{|c|c|c|c|c|c|c|c|c|}
\hline \multirow{2}{*}{ Patients } & \multirow{2}{*}{ Age } & \multicolumn{4}{|c|}{ Vital signs } & \multirow{2}{*}{$\begin{array}{l}\text { HRV } \\
\text { pattern }\end{array}$} & \multirow{2}{*}{ ANS -Assessment } & \multirow{2}{*}{ Etiopathology } \\
\hline & & $\mathrm{HR}$ & SBP & DBP & RR & & & \\
\hline P-212 & 36 & 49 & 120 & 45 & 16 & $\mathrm{C}$ & $\uparrow \mathrm{Ps}$ & SS-HypEnceph \\
\hline P-213 & 43 & 80 & 160 & 80 & 15 & A & $\uparrow S$ & CVE-SH \\
\hline P-218 & 74 & 107 & 80 & 40 & 14 & B & ADys-A & SS-ARI \\
\hline P-220 & 64 & 122 & 80 & 40 & 15 & B & ADys-A & BA-HypEnceph \\
\hline P-253 & 59 & 100 & 140 & 70 & 15 & $\mathrm{D}$ & $\uparrow S$ & CVE-SH \\
\hline P-323 & 74 & 73 & 170 & 100 & 16 & $\mathrm{C}$ & $\uparrow S$ & CVE-ICI \\
\hline P-354 & 42 & 107 & 120 & 70 & 14 & $\mathrm{D}$ & $\uparrow \uparrow S$ & SS-ESt \\
\hline P-405 & 54 & 112 & 65 & 40 & 16 & B & ADys-A & Cf-ESt \\
\hline P-415 & 52 & 73 & 130 & 60 & 14 & B & steady & UI-SS \\
\hline P-421 & 34 & 108 & 200 & 80 & 14 & $\mathrm{D}$ & $\uparrow \uparrow S$ & CVE-IBH \\
\hline P-443 & 52 & 102 & 120 & 90 & 15 & A & $\uparrow S$ & SS-HypEnceph \\
\hline P-503 & 75 & 48 & 155 & 60 & 15 & A & ADys-B & MetEnceph-ARI \\
\hline P-515 & 55 & 73 & 80 & 60 & 14 & A & $\downarrow S$ & SH-SS \\
\hline P-530 & 75 & 77 & 120 & 90 & 15 & A & $\uparrow S$ & CVE-SH \\
\hline P-543 & 33 & 113 & 140 & 70 & 16 & B & $\uparrow S$ & CVE-SH \\
\hline P-547 & 74 & 102 & 110 & 90 & 14 & A & $\uparrow S$ & TBI-SH \\
\hline
\end{tabular}

Note. HR, heart rate; SBP, systolic blood pressure; DBP, diastolic blood pressure; RR, respiratory rate obtained from values of the automatic ventilator; HRV pattern: A, power spectral density (PSD) present but limited to a peak of the VLF, the HF or the VHF band; B, markedly reduced values of PSD $\left(<1000 \mathrm{~ms}^{2}\right)$ of HRV spectra without evidence of relevant peaks assessed by the Fisher's g Statistic; C, reduced values of PSD values $\left(1000-6000 \mathrm{~ms}^{2}\right)$ with identifiable peaks in the VLF and LF bands; D, PSD values higher than $6000 \mathrm{~ms} 2$ with identifiable peaks; Ps, parasympathetic; S, sympathetic; ADys-A, autonomic dysregulation type A (SBP $\leq 80$ and HR $>100$ ); ADys-B, autonomic dysregulation type B (SBP > 150 and HR < 50); ANS, autonomic nervous system; ARI, acute renal insufficiency; BA, bronchial asthma; Cf, craniopharyngioma; CVE, cerebrovascular event; ESt, epileptic status; HypEnceph, hypoxic encephalopathy; IBH, intraparenchymatous brain hemorrhage; ICI, ischemic cerebral infarct; MetEnceph, metabolic encephalopathy; SH, subarachnoid hemorrhage; SS, septic shock; TBI, traumatic brain injury; UI, urinary infection. 
Table 7. Comparison of clinical and heart rate variability variables between patients in coma who survived and those who died at 3 months.

\begin{tabular}{|c|c|c|c|c|}
\hline Variables & $\begin{array}{l}\text { Survivors } \\
(\mathrm{n}=27)\end{array}$ & $\begin{array}{l}\text { Non-survivors } \\
\quad(\mathbf{n}=\mathbf{2 0})\end{array}$ & $F(1,45)$ & $\mathbf{p}$ \\
\hline GCS (score) & $5.58 \pm 1.9$ & $4.70 \pm 1.6$ & 2.918 & 0.09 \\
\hline Age (years) & $52.33 \pm 16.8$ & $56.69 \pm 16.4$ & 0.810 & 0.37 \\
\hline SBP (mmHg) & $125.4 \pm 33$ & $118.7 \pm 21$ & 0.670 & 0.42 \\
\hline $\mathrm{DBP}(\mathrm{mmHg})$ & $77.1 \pm 23$ & $70.4 \pm 14$ & 1.363 & 0.25 \\
\hline Respiratory Rate (cycles/min) & $18.71 \pm 5.1$ & $19.87 \pm 4.7$ & 0.625 & 0.43 \\
\hline MRRi (ms) [Adj] & $-31.4 \pm 145$ & $-103.1 \pm 115$ & 3.474 & 0.07 \\
\hline $\log _{10} \operatorname{SDRR}(\mathrm{ms})[\mathrm{Adj}]$ & $0.0168 \pm 0.341$ & $-0.1850 \pm 0.349$ & 3.948 & 0.053 \\
\hline $\log _{10} \operatorname{RMSSD}(\mathrm{ms})[\mathrm{Adj}]$ & $-0.0637 \pm 0.339$ & $-0.0750 \pm 0.406$ & 0.110 & 0.92 \\
\hline nDRRs (n) & $83.66 \pm 44.5$ & $43.85 \pm 40.70$ & 9.884 & 0.006 \\
\hline Sha-Ent (CU) [Adj] & $0.0787 \pm 1.142$ & $-0.6420 \pm 1.074$ & 4.816 & 0.03 \\
\hline Ln P-VLF $\left(\mathrm{ms}^{2}\right)$ [Adj] & $0.3445 \pm 1.412$ & $-1.1540 \pm 2.060$ & 7.047 & 0.01 \\
\hline Ln P-LF $\left(\mathrm{ms}^{2}\right)[\mathrm{Adj}]$ & $0.2350 \pm 2.207$ & $-1.2610 \pm 2.063$ & 5.579 & 0.02 \\
\hline Ln P-HF $\left(\mathrm{ms}^{2}\right)$ [Adj] & $-0.0146 \pm 1.844$ & $-0.8510 \pm 1.673$ & 2.551 & 0.12 \\
\hline Ln P-VHF $\left(\mathrm{ms}^{2}\right)$ & $9.0983 \pm 1.530$ & $9.2490 \pm 2.089$ & 0.081 & 0.78 \\
\hline Ln P-Tot $\left(\mathrm{ms}^{2}\right)$ [Adj] & $0.1127 \pm 1.665$ & $-0.8590 \pm 1.668$ & 3.906 & 0.05 \\
\hline nu-VLF (\%) & $32.82 \pm 18.9$ & $20.41 \pm 13.2$ & 6.320 & 0.01 \\
\hline nu-LF (\%) [Adj] & $5.7083 \pm 17.02$ & $-11.0361 \pm 11.620$ & 14.351 & 0.004 \\
\hline nu-HF (\%) [Adj] & $-3.5246 \pm 17.35$ & $1.4470 \pm 18.669$ & 0.884 & 0.35 \\
\hline nu-VHF (\%) [Adj] & $-8.5429 \pm 9.93$ & $14.24 \pm 20.7$ & 25.148 & 0.0001 \\
\hline $\log _{10} \mathrm{LF} / \mathrm{HF}$ ratio & $0.6261 \pm 1.275$ & $-0.1040 \pm 1.568$ & 3.098 & 0.08 \\
\hline cf-IMF-2 (Hz) [Adj] & $0.0250 \pm 0.061$ & $0.0050 \pm 0.029$ & 1.877 & 0.18 \\
\hline cf-IMF-3 (Hz) & $-0.0045 \pm 0.035$ & $0.0080 \pm 0.039$ & 1.270 & 0.27 \\
\hline cf-IMF-4 (Hz) & $0.1238 \pm 0.020$ & $0.1270 \pm 0.015$ & 0.466 & 0.49 \\
\hline
\end{tabular}

Note. Values are presented as means \pm standard deviations; abbreviations for HRV indices are detailed in Methods; [Adj], adjusted values; CU, conventional units; NU, non-dimensional units; F, Fisher's F statistic for the one-way ANOVA tests; $p$, associated probability to the $\mathrm{F}$ values. 
Table 8. Results of the stepwise multivariate regression analysis for the prediction of mortality in the patients included in this study.

\begin{tabular}{|l|c|c|c|c|c|c|c|}
\hline \multirow{2}{*}{ Variables } & \multirow{2}{*}{$\mathrm{B}$} & \multirow{2}{*}{$\mathrm{SE}$} & \multirow{2}{*}{ Wald } & \multirow{2}{*}{$\mathrm{p}$} & \multirow{2}{*}{ OR } & \multicolumn{2}{|c|}{ 95\% CI for OR } \\
\cline { 7 - 9 } & & & & & & Lower & Upper \\
\hline nu-VHF & 0.558 & 0.285 & 3.826 & 0.045 & 1.747 & 0.999 & 3.054 \\
\hline P-LF & -2.164 & 1.196 & 3.276 & 0.070 & 0.115 & 0.011 & 1.197 \\
\hline P-VLF & 1.585 & 1.053 & 2.264 & 0.132 & 4.878 & 0.619 & 38.435 \\
\hline Constant & 9.378 & 4.197 & 4.993 & 0.025 & 11.827 .1 & - & - \\
\hline
\end{tabular}

Note. B, coefficient of the regression equation; SE, standard error; Wald, Wald chi-squared statistic; $p$, significance of Wald statistic; OR, odds ratio; CI, confidence interval. 